\title{
Do Negative Economic Shocks Affect Cognitive Function, Adherence to Social Norms and Loss Aversion?
}

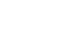

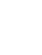

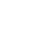

Keywords: cognitive function; cheating; social norm; loss aversion; negative shock; income; asset.

JEL Classification: C91; D91; D81

\author{
Francesco Bogliacino \\ Corresponding author \\ Universidad Nacional de Colombia \\ Centro de Investigaciones para el Desarrollo (CID) \\ Felipe Montealegre \\ Universidad Nacional de Colombia \\ Centro de Investigaciones para el Desarrollo (CID)
} \begin{abstract}
Households are frequently subject to income and asset shocks. We performed a lab
experiment, inducing losses on a real effort task, after which we measured cognitive performance, loss aversion and cheating behavior. We found that asset losses, but not income losses, act as a cognitive load, by decreasing accuracy and increasing response times. We did not detect any change in dishonesty or loss aversion.

Abstract
\end{abstract}




\section{Introduction}

In both developed and developing countries, it is common for households to face sudden negative changes to their income and wealth. Economists call these Negative Economic Shocks (NES). They can occur in the form of either Negative Income Shocks (NIS), when income flows such as earnings are negatively affected by an event, or Negative Wealth Shocks (NWS), when the value of accumulated assets is reduced.

We wish to understand how negative income and wealth shocks affect cognitive function, whether this cognitive toll affects preferences toward risk in the loss domain and cheating, and whether asset or earning losses have similar consequences (to date they are treated interchangeably in the literature).

To address these questions, we perform an incentivized controlled experiment. We randomly induce NIS and NWS to participants, by altering either the pay rate of a two-rounds Real Effort Task (RET), or the accumulated earnings from the first to the second round. We then measure fluid intelligence, short term memory, cheating, and loss aversion.

Cognitive function is the ability to process information in order to perform the tasks of reasoning, comprehension and learning, and which require a reliance on processes that are neither automatic nor based on instinct (Baddeley \& Hitch, 1974; Diamond, 2013). It is recognized that the human cognitive system has a limited capacity (Kahneman, 2011). As a result, differences in cognitive function determine the capacity for information processing and the performance of subjects in decision tasks. NES are expected to act as a cognitive load. This is consistent with the findings of Mani et al. (2013), who find that inducing scarcity in the lab through priming financial worries or exploiting a natural variation of income for sugar cane farmers-due to having to queue for the product to be processed-reduces cognitive function. A similar finding is in Bogliacino et al. (2017), where exposure to violence- associated with NES-shows a reduction in cognitive control and short term memory.

Dishonesty is a moral infraction motivated by a personal or group advantage or the reduction of a potential harm. Using incentivized tasks (e.g., Fischbacher and Follmi-Heusi, 2013), experimental economists study situations in which a subject can increase her payoff by lying or deceiving. These tasks have shown to be externally valid (Dai et al. 2018). We are interested in cheating because it does not depend on strategic consideration and has a clear social norm associated with. A social norm is a behavior whose choice by the agent is causally affected by beliefs over what others will do (empirical expectations) and what others think should be done (normative expectations) (Bicchieri, 2017). Shocks can increase cheating, because they may shift either normative or empirical expectations, or because-to the extent that adherence is a prosocial behavior, which is a normal good-losses alter the opportunity cost of being pro-social, or because they change the relative magnitude of costs and benefits of the action, as predicted by rational models (Becker, 1968; Ehrlich, 1973). In fact, cheating can be less costly when people have to face losses, which could potentially explain why shocks are associated with anti-social behavior (Aksoy \& Palma, 2019). 
Loss aversion is the cornerstone of the Prospect Theory model of Kahneman and Tversky (1979). Broadly speaking, it refers to assigning a larger weight to losses from a reference point, with respect to gains of equal magnitude when making decisions (Fox \& Poldrack, 2009). By making a loss salient, NES may shift risk preferences in the loss domain. This is consistent with the results of Pammi et al. (2017). Moreover, subjects facing losses in the lab are more likely to show present bias and hyperbolic discounting (Haushofer, Schunk, \& Fehr, 2013), which is correlated with loss aversion (Dean \& Ortoleva, 2019).

The current literature on shocks does not properly distinguish between income and asset shocks. Looking at the separate and joint effects of income and asset shocks is our first contribution. To the best of our knowledge, this is the first paper that explicitly looks at the cognitive impact of shocks, using experimental manipulation and not natural exogenous variation. Additionally, we analyze whether negative shocks, and the cognitive load induced by them, drives behavioral change, for which evidence is lacking in the literature (Kremer et al. 2019). Finally, by analyzing dishonesty, we provide the first experimental evidence on whether shocks induce anti-social behavior, whereas most of the existing literature is quasi-experimental.

\section{Methods}

We used five different tasks in the experiment. The first was a Real Effort Task (RET) and was instrumental in introducing the experimental treatments. Participants performed two rounds of this task, and losses were introduced after the first round, manipulating either the pay rate (NIS), the accumulated earnings (NWS) or both. We used the Niederle and Vesterlund (2007) version of RET (summing sequences of two-digit numbers), because it has a cognitive component, and the second round can be used to measure cognitive function.

The other two tasks used to measure cognitive function are the Short-Term Memory (STM) task by Bogliacino et al. (2017) and a subset of Raven's matrices to measure Fluid Intelligence (FI). STM is the capacity to store information and maintain certain items above the threshold of activation, even without it being the focus of attention (Baddeley \& Hitch, 1974; Engle, Laughlin, Tuholski, \& Conway, 1999). In the STM task, participants were shown a $5 \times 4$ matrix with 20 geometrically impossible images. Participants had 30 seconds to remember the images. Once the 30 seconds expired, participants had to solve 20 problems. Each of these problems consisted of a set of three images, and the participants had to recognize which one appeared in the original set.

Fluid intelligence is the ability to solve novel problems and corresponds to the higher-level executive function of reasoning and problem-solving (Diamond, 2013). The FI test involves a sequence of shapes with one missing, which should be selected from amongst five options.

To measure cognitive function avoiding multiple hypotheses testing, we standardize the accuracy in the second round of the Real Effort Task, the STM test and the FI test, and we pool together the data in panel form (this is equivalent to averaging them with equal weights). For the three tasks, we also measure response time, as a proxy of cognitive processing.

Loss Aversion (LA) is measured through a six-items lottery task based on Gächter et al. (2010). The lotteries have two possible outcomes (a win and a loss, equally likely), and can be accepted or rejected; in the latter case the payoff is zero. The six lotteries are presented in a 
Multiple Price List format, with decreasing expected value, which is negative for the last one. Since for small stakes, participants are likely to be risk neutral, we can interpret the rejection of lotteries involving losses but with a positive expected value as a proxy for loss aversion (Rabin, 2000). The higher the rejected expected value, the higher the loss aversion.

To measure dishonesty, participants played the "cheating game" (CG), based on Fischbacher \& Föllmi-Heusi (2013). Participants are asked to roll a die privately and to report the results. Payment increases in the reported number up to five and is equal to zero in the case of six.

We recruited 282 undergraduate students from the Universidad Nacional de Colombia, with an average age of 22 years. The average session had around 17 participants, and there were 17 sessions in total. After entering the lab, participants were seated in front of a computer and had to sign a consent form. Instructions were read aloud.

Participants were told that the experiment was composed of two parts. In the first part, they had to perform the RET. In the second part, they had to perform four other tasks and complete a questionnaire.

Participants were aware that the outcome of the first part (i.e., the two rounds of RET) would always be paid, while for the second part, they would be paid randomly for one of the four tasks. The latter would be selected at random at the end of the session by one participant using an urn with four colored balls. They also knew since the beginning that they could be subject to a shock.

After reading the general instructions, we asked participants to follow instructions on the computer screen. The experiment was programmed with oTree (Chen et al., 2016). Each of the tasks contained its own instructions and participants were told they could raise their hand at any time if they had any questions. The experimental protocol with the informed consent and the instructions for each of the tasks can be found in the SI, Section S1.

Experimental treatments were administered at the end of the first round of the RET. NWS was implemented as a $50 \%$ loss on the accumulated earnings from the first round, while a NIS was a $50 \%$ reduction of the points per correct sum in the second round. NWS-NIS was the combination of the two. For the control condition, neither the accumulated earnings nor the pay per sum was affected. Participants were aware that earnings could change after the first round. At the end of the first round of RET, all participants were informed of the earnings accumulated and the shock received, and at the end of the second round, of the performance in each addition in rounds one and two, and the earnings and loss associated with the RET.

Then participants move to the second part, where they are asked to perform the STM task, the FI task, the CG task, and the LA task. We randomly assigned feedback on the results of the tasks in the second part of the experiment, at the session level. Two thirds of the sessions were with feedback of the results in the tasks of the second part. In other words, while everybody saw their performance, earnings, and loss in the RET, participants in the sessions with feedback saw their results after each task in the second part, whereas those in the sessions without feedback did not visualize the results of the task before moving to the following one. We will not analyze the feedback treatment in this paper, but we include it in all the analyses.

There are two issues worth noting in the experimental design related to the payment procedure. First, the currency for the RET was the point (1,000 per correct answer), while for the other tasks we used Experimental Currency Unit (ECU). We did this to make sure that the 
shock affected only part I of the experiment and to make the separation between the first and second part of the experiment more salient. Second, we paid the RET to make the treatment salient, and a randomly chosen one among the remaining four. The exchange rates were 1 COP per point and 1,000 COP per ECU. On average each participant earned 18,100 COP, with a standard deviation of 6,100 COP. At the time of the study, one USD was approximately worth 3,000 COP. When all of the participants had completed the last task, we asked for a volunteer to draw one of the tasks for payment-from amongst the four tasks of the second part of the experiment-using a black urn and four colored balls. A final questionnaire was handed out to the participants.

Because participants had to perform five different tasks, we had to control for order effects. However, because we had to introduce the experimental treatments before the other tasks, the RET was played always in the first place. Since in the LA task, participants were initially endowed with seven ECU to cover potential losses, this was always played as the last task, because the initial endowment may work as a positive economic shock and we wanted to avoid possible contaminations. There were six orders in total in which we presented the tasks and we report the possible orders in SI, Section S4, Table S14.

For all measures, we ran Ordinary Least Squares regressions, with Huber-White robust standard errors, using as the following control variables: gender, age, the order in which the tasks were presented, a dummy for the sessions where we used feedback, whether or not the participants were studying an undergraduate program with math-related training, sociodemographic characteristics, such as the ranking in the socio-economic stratification system used in Colombia (Bogliacino, Jiménez Lozano, \& Reyes, 2018), and a question on how easily participants are able to face a sudden large expenditure (see SI, Section S3.2, Table S4).

\section{Results}

Out of the 282 participants, we had to exclude two because they did not complete the questionnaire. The distribution of participants across treatments is the following: 76 in control, 72 in NIS only, 69 in NWS only, 65 in NWS and NIS combined. 212 were in sessions with feedback, whereas 70 were in sessions without feedback. In the first round of the RET there is no difference in accuracy across conditions, before administering the shocks (SI Table S1, column 4).

Cognitive performance in the experiment is plotted in Figure 1, together with significance levels from an Ordinary Least Squares regression, pooling all the measures, with controls and robust standard errors (see equation [S1] in SI, Section S3). We emphasize that accuracy is standardized, thus deviation from the zero line can be interpreted in percentage of standard deviation. On the x-axis, we have the four experimental conditions. In Table 1, we highlight the key results from those regressions, and full results are available in SI, Table S5. T-tests are computed from the regression analysis.

Performance decreases under all shock conditions. The difference is statistically significant for NWS alone $(\mathrm{t}(824)=-2.62, \mathrm{p}=0.009)$ and NWS and NIS combined $(\mathrm{t}(824)=-1.92, \mathrm{p}=$ $0.055)$. 
The performance can be broken down in the following way. In the RET, participants in the control condition make on average 6.36 correct additions, while they have 5.96 in the NIS only, 5.67 in the NWS only and 6.09 under combined shocks. In the STM, participants correctly recall 13.76 figures in the control condition, while they have 14.07 in the NIS only, 13.49 in the NWS only and 12.75 under combined shocks. In the FI, participants correctly solve 4.05 sequences in the control condition, while they have 3.92 in the NIS only, 3.78 in the NWS only and 3.95 under combined shocks.

Results are robust when we exclude the second round of the RET, including only STM and FI. Results are also robust to the use of other procedures for pooling data, such as using principal component analysis and extracting the first component $(\mathrm{KMO}=0.52$, the eigenvalue of the first component is 1.37 , and the variance explained accounts for $45.71 \%$ of the total). Principal component analysis is equivalent to representing the variable space through a set of uncorrelated variables, building a score variable through the weights taken from the eigenvector associated with the largest eigenvalue. Results are also robust to adding the performance in the first RET round as control (SI, Section S3, Table S6).

By analyzing the response time, we can see whether choice processing is consistent with cognitive depletion. Since time is fixed, we consider how much a participant requires per question to accomplish half of the average performance in each task, and then standardize the response time through a $\mathrm{z}$-score transformation (subtracting the mean and dividing by the standard deviation). Average time is increasing from control to income shock condition ( $t(824)$ $=1.07, \mathrm{p}=0.286)$, to wealth shock condition $(\mathrm{t}(824)=1.73, \mathrm{p}=0.084)$ and to combined shocks $(\mathrm{t}(824)=2.46, \mathrm{p}=0.014)$.

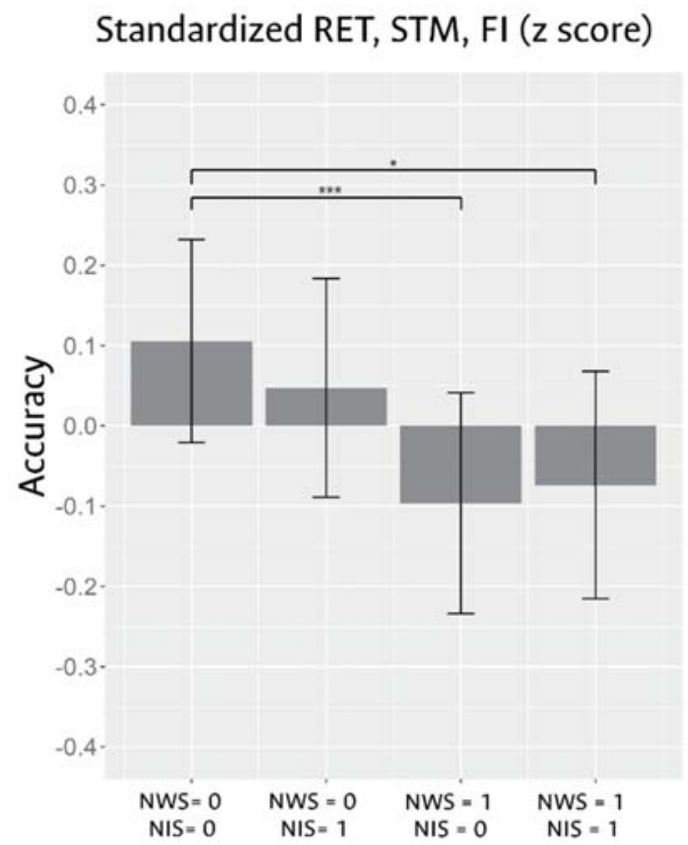

Fig. 1: Accuracy in cognitive tasks across experimental conditions. Gray vertical bars show standardized accuracy for each of the treatment groups. Error bars show $95 \%$ confidence interval for the mean. Top horizontal bars show statistical significance of tests on the null hypothesis that accuracy is the same with respect to control as per regressions with a set of individual controls. See SI, Table S3. ${ }^{* * *} \mathrm{p}<0.01,{ }^{* *} \mathrm{p}<0.05,{ }^{*} \mathrm{p}<0.1$. 
Table 1: Mean difference with respect to control on standardized and per-task accuracy and response time conditional on a number of exogenous control variables.

\begin{tabular}{|l|c|c|c|c|c|c|}
\hline & \multicolumn{7}{|c|}{ Accuracy } & Response Time \\
\hline & $\begin{array}{c}\text { Cognitive } \\
\text { Index }\end{array}$ & STM-FI & RET & STM & FI & $\begin{array}{c}\text { Cognitive } \\
\text { Index }\end{array}$ \\
\hline NWS=0 & -0.084 & -0.035 & -0.427 & 0.217 & -0.179 & 0.097 \\
NIS=1 & $(0.094)$ & $(0.114)$ & $(0.389)$ & $(0.478)$ & $(0.196)$ & $(0.090)$ \\
\hline NWS= & $-0.247^{* * *}$ & $-0.216^{*}$ & $-0.721^{*}$ & -0.440 & $-0.348^{*}$ & $0.163^{*}$ \\
NIS=0 & $(0.094)$ & $(0.116)$ & $(0.380)$ & $(0.476)$ & $(0.207)$ & $(0.094)$ \\
\hline NWS=1 & $-0.182^{*}$ & $-0.207^{*}$ & -0.305 & $-1.054^{* *}$ & -0.066 & $0.240^{* *}$ \\
NIS=1 & $(0.095)$ & $(0.115)$ & $(0.393)$ & $(0.466)$ & $(0.204)$ & $(0.097)$ \\
\hline Mean Control & 0.105 & 0.087 & 6.355 & 13.763 & 4.052 & -0.104 \\
\hline Observations & $(0.064)$ & $(0.079)$ & $(0.255)$ & $(0.329)$ & $(0.138)$ & $(0.060)$ \\
\hline
\end{tabular}

Note: The table reports results from econometric analysis to explain the degree of standardized accuracy (including and excluding RET), per-task accuracy, and response time of treatments with respect to control. Cognitive index includes RET (Real Effort Task), STM (Short Term Memory task), FI (Fluid Intelligence Task). Linear regression models have been fitted with a series of individual controls. Robust SE reported in parenthesis. See SI, Section S3.2. ${ }^{* * *} \mathrm{p}<0.01,{ }^{* *} \mathrm{p}<0.05,{ }^{*} \mathrm{p}<0.1$.

Notice that, according to Table S5, women perform worse in these cognitive tasks, a result we were not expecting. Participants from richer neighborhoods perform better, a result that did not surprise because they are more likely to have access to other sources of education or learning via their parents or their peers, or to have had access to a better secondary education, in a country with highly heterogeneous education quality and in a city with very high residential segregation.

On the other hand, we do not find significant changes in cheating or loss aversion. Starting with the former, we plot the cumulative density function per experimental condition in Figure 3 below. Notice that although we cannot directly see if the participant was cheating, we can compare the distribution with a uniform one: the results clearly reject the null hypothesis of a lack of cheating behavior. To test whether participants over-reported numbers four or five (returning the highest payoff), we simulated a random draw of a die from a uniform distribution for the same number of participants, with 100,000 repetitions. While in the real data, $47.52 \%$ of participants in the experiment reported the highest payoff numbers, none of the simulated samples had a greater or equal proportion. The estimated p-value is lower than 0.00001 . A chisquare test comparing the observed distribution versus the expected one under the assumption of a fair die confirms the main finding $\left(\chi^{2}(5)=30.72, \mathrm{p}<0.001\right.$, see SI, Section 3.4, Table S12). To identify whether this cheating is different across conditions, we perform a chi-square test under the null hypothesis of equality of distributions. Even without controlling for multiple hypotheses testing, the null cannot be rejected $\left(\chi^{2}(15)=10.27, \mathrm{p}=0.80\right)$. Results are reported in SI, Section 3.4, Table S13. For symmetry with the other variables, we perform OLS regressions over the likelihood to report four or five. The likelihood is not statistically different between exposure to shock and control: in control conditions, $46.05 \%$ of the participants report four or five, whereas it is $50 \%$ in the income shock condition, $44.93 \%$ in the wealth shock condition and $49.23 \%$ under combined shock. The results can be seen in SI, Section S3.2, Table S8.

Finally, in Table 2, we report the results of the regression analysis for the three variables that were measured in the loss aversion task: the likelihood of being loss averse, the switching point 
1 from accepting to rejecting a lottery (a measure of the degree of loss aversion) and the number 2 of rejected lotteries (another proxy of the degree, and for which we do not have to discard 3 multiple switchers). There are no significant differences across conditions. The likelihood of 4 being loss averse in the control condition is $86.8 \%$, while it is $91.2 \%$ in the income shock 5 condition, $87.9 \%$ in the wealth shock condition and $83.3 \%$ in the combined shock. The lottery 6 of the single switch is on average 2.94 in the control condition, 2.84 in the income shock 7 condition, 2.95 in the wealth shock condition, and 2.87 in the combined shock. To conclude, 8 the average number of rejections is 3.09 in the control condition, 3.13 in the income shock 9 condition, 3.10 in the wealth shock condition, and 3.12 in the combined shock.

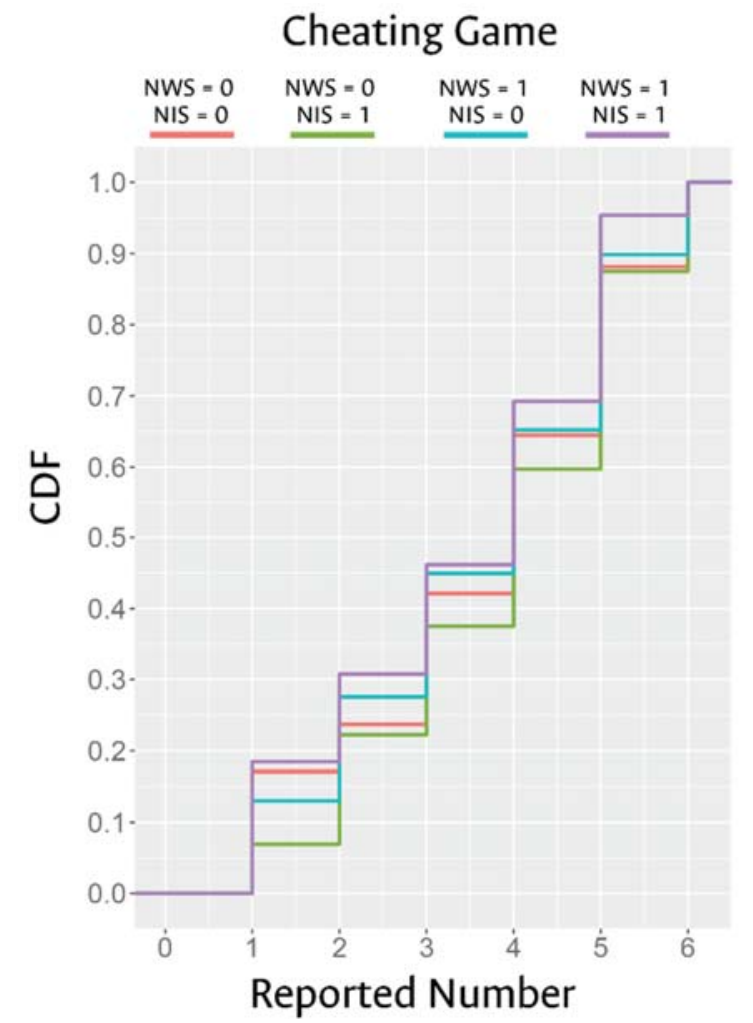

Fig. 2: Cumulative density function of each of the experimental groups including control. 
Table 2: Mean difference with respect to control of likelihood of being loss averse, the switching point from accepting to rejecting a lottery, and the number of rejected lotteries.

\begin{tabular}{|l|l|l|l|}
\hline & $\begin{array}{c}\text { Share of } \\
\text { Loss Averse }\end{array}$ & Switching point & $\begin{array}{c}\text { Number of } \\
\text { Rejected } \\
\text { Lotteries }\end{array}$ \\
\hline $\begin{array}{l}\text { NWS }=0 \\
\text { NIS }=1\end{array}$ & 0.044 & -0.103 & 0.038 \\
NWS $=1$ & $0.058)$ & $(0.246)$ & $(0.210)$ \\
NIS $=0$ & 0.006 & 0.042 & 0.017 \\
\hline NWS $=1$ & $(0.063)$ & $(0.264)$ & $(0.235)$ \\
NIS=1 & -0.024 & -0.153 & 0.124 \\
\hline Mean Control & $(0.063)$ & $(0.262)$ & $(0.239)$ \\
\hline Observations & 0.867 & 2.941 & 3.092 \\
\hline
\end{tabular}

Note: The table reports results from econometric analysis to explain the likelihood of being loss averse, the switching point from accepting to rejecting a lottery, and the number of rejected lotteries of treatments with respect to control. Linear regression models have been fitted with a series of individual controls. Robust SE reported in parenthesis. See SI, Section S3.2. *** $\mathrm{p}<0.01,{ }^{* *} \mathrm{p}<0.05,{ }^{*} \mathrm{p}<0.1$.

Given that the negative effect of shocks appears to be driven by NWS and data are not consistent with the hypothesis of an interaction between NIS and NWS, we again run all the analyses, focusing on the main effect of both treatments. For the main effect, the dummy for income shock is equal to one for treatment group one (NIS=1, NWS $=0$ ) and for treatment group three (NIS=1, NWS=1), and the dummy for wealth shock is equal to one for treatment group two (NIS=0, NWS=1) and treatment group three (NIS=1, NWS=1). Random and independent assignment of the two shocks allows separate identification of their impact. Cognitive performance is significantly lower for participants exposed to NWS with respect to control $(\mathrm{t}(825)=-2.59, \mathrm{p}=0.010)$. Results are robust when we exclude, from the cognitive index, the second round of the RET, and when we extract the cognitive index through principal component analysis. Response time is also increasing $(\mathrm{t}(825)=2.25, \mathrm{p}=0.025)$. No effect is detected for NIS. In SI, Section 3.3 Table S9, we report this set of regressions. On the contrary, there is no effect of either NWS or NIS in the propensity to report four or five in the cheating game (SI, Section 3.3, Table S11). In SI, Section 3.3, Table S10, we report our three measures of loss aversion. We could not detect any effect of NWS or NIS.

Our final concern is for power. Lack of evidence is not evidence of no impact. In SI, Section $\mathrm{S} 5$, using standard power analysis, we show that ex ante our sample was appropriate to detect a small-to-medium impact in both loss aversion and cheating. We also perform equivalence tests (Lakens, 2017; Dinno, 2017) to reject the null hypothesis that the non-significant effect is larger than half a standard deviation; in other words, we assess whether $\left|\mu_{N W S}-\mu_{C T R L}\right|>\Delta$ (where the two means are those for the NWS and the control, and $\Delta$ is half the standard deviation). We found that, for both the number of rejected lotteries and the likelihood to report 4 or 5 (see SI, Section S5, Tables S15-S16) the effect is equivalent to zero within the specified range.

\section{Discussion}

Our results provide evidence that being affected by a negative economic shock acts as a cognitive load. The effect seems to be driven by negative asset shocks, and not by negative 
income shocks, as per our results. The relative magnitude of the two sources of shocks may be the discriminant factor behind this difference. Alternatively, assets can play a different role in terms of households' safety net and shocks affecting them may be more salient. ${ }^{1}$ On the contrary, neither cheating nor loss aversion are significantly affected by exposure to shocks.

The literature has argued that anti-social behavior may be driven by contextual factors, such as shocks, and not only by individual traits (Sharkey et al., 2016; Cortés et al., 2016; Bignon et al., 2017). Our results do not support the main tenet of this literature, although they are not conclusive.

Our results also have implications for the study of poverty. Based on our results and those of Haushofer and Fehr (2014), poverty affects behavior mainly through cognitive load and changes in temporal discount rate (impatience). It is important to compare our results with Carvalho et al. (2016). Using a before-after paycheck natural variation, they found an effect of scarcity on present bias, but not on risk preferences or cognition. First of all, the manipulation used in the two studies is different: although paycheck is more salient and externally valid, it is-in the authors' words-temporary, expected and expected to be temporary, whereas ours is certainly smaller but is permanent and ex ante uncertain. In terms of risk preferences, we look at the loss domain while they look at the gain domain, but the results are similar, although in our case, we can only exclude that the effect if large. Finally, they did not detect cognitive load, while we did.

There are at least two main limitations in our study. First, we have prioritized internal over external validity, and this may harm generalization. Second, a fifty percent shock over a real effort task may be limited with respect to a real-life shock. This should caution us that we are estimating a lower bound.

\section{Acknowledgements}

We acknowledge financial support from Internal Grant Convocatoria Jesus Antonio Bejarano 2017. We thank the Managing Editor, Maria Bigoni, Dirk Engelmann and two anonymous referees for their careful reading and suggestions. We appreciate comments from all participants at the BEBES seminar in Bogotá, the Bogotá Experimental Economics Conference 2019 and the ESA World Congress 2019. We thank Silvia López, César Mantilla, Lina Moros who commented on Felipe's Master thesis which was part of this work. We are also thankful to Marco Palma, Patrick Ring, Gianluca Grimalda, Camilo Gómez, and Nicolás Rodriguez for their comments and suggestions. Thanks also to Natalí Barrera and Laura Jiménez who helped with the experiments.

\section{References}

Aksoy, B., \& Palma, M. A. (2019). The effects of scarcity on cheating and in-group favoritism. Journal of Economic Behavior \& Organization, 165, 100-117. https://doi.org/10.1016/j.jebo.2019.06.024

Baddeley, A. D., \& Hitch, G. (1974). Working Memory. Psychology of Learning and Motivation, 8,

\footnotetext{
${ }^{1}$ We thank Marco Palma for this observation.
} 
47-89. https://doi.org/10.1016/S0079-7421(08)60452-1

Becker, G. S. (1968). Crime and Punishment: an Economic Approach. In The Economic Dimensions of Crime (pp. 13-68). https://doi.org/10.1007/978-1-349-62853-7_2

Bicchieri, C. (2017). Norms in the Wild. In Norms in the Wild: How to Diagnose, Measure, and Change Social Norms. https:/ / doi.org/10.1093/acprof:oso/9780190622046.001.0001

Bignon, V., Caroli, E., \& Galbiati, R. (2017). Stealing to Survive? Crime and Income Shocks in Nineteenth Century France. The Economic Journal, 127(599), 19-49. https://doi.org/10.1111/ecoj.12270

Bogliacino, F., Grimalda, G., Ortoleva, P., \& Ring, P. (2017). Exposure to and recall of violence reduce short-term memory and cognitive control. Proceedings of the National Academy of Sciences, 114(32), 8505-8510. https://doi.org/10.1073/pnas.1704651114

Bogliacino, F., Jiménez Lozano, L., \& Reyes, D. (2018). Socioeconomic stratification and stereotyping: lab-in-the-field evidence from Colombia. International Review of Economics, 65(1), 77-118. https://doi.org/10.1007/s12232-017-0285-4

Carvalho, L. S., Meier, S., \& Wang, S. W. (2016). Poverty and Economic Decision-Making: Evidence from Changes in Financial Resources at Payday. The American Economic Review, 106(2), 260-284. https://doi.org/10.1257/aer.20140481

Chen, D. L., Schonger, M., \& Wickens, C. (2016). oTree-An open-source platform for laboratory, online, and field experiments. Journal of Behavioral and Experimental Finance, 9 , 88-97. https://doi.org/10.1016/j.jbef.2015.12.001

Cortés, D., Santamaría, J., \& Vargas, J. F. (2016). Economic shocks and crime: Evidence from the crash of Ponzi schemes. Journal of Economic Behavior and Organization, 131, 263-275. https://doi.org/10.1016/j.jebo.2016.07.024

Dai, Z. , Galeotti, F., Villeval, M.C., (2018).Cheating in the lab predicts fraud in the field: an experiment in public transportation. Management Science, 64(3): 1081-1100

Dean, M., \& Ortoleva, P. (2019). The empirical relationship between nonstandard economic behaviors. Proceedings of the National Academy of Sciences, 116(33), 16262-16267. https://doi.org/10.1073/pnas.1821353116

Diamond, A. (2013). Executive Functions. Annual Review of Psychology, 64(1), 135-168. https://doi.org/10.1146/annurev-psych-113011-143750

Ehrlich, I. (1973). Participation in Illegitimate Activities: A Theoretical and Empirical Investigation. Journal of Political Economy, 81(3), 521-565. https://doi.org/10.1086/260058

Elster, J. (1989). Social Norms and Economic Theory. The Journal of Economic Perspectives, Vol. 3, pp. 99-117. https://doi.org/10.2307/1942912

Engle, R. W., Laughlin, J. E., Tuholski, S. W., \& Conway, A. R. A. (1999). Working memory, short-term memory, and general fluid intelligence: A latent-variable approach. Journal of Experimental Psychology: General. https://doi.org/10.1037/0096-3445.128.3.309

Fischbacher, U., \& Föllmi-Heusi, F. (2013). Lies in disguise. An experimental study on cheating. Journal of the European Economic Association, 11(3), 525-547. https://doi.org/10.1111/jeea.12014

Fox, C. R., \& Poldrack, R. A. (2009). Prospect Theory and the Brain. In Neuroeconomics (pp. 145-173). https://doi.org/10.1016/B978-0-12-374176-9.00011-7

Gächter, S., Johnson, E. J., \& Herrmann, A. (2010). Individual-level loss aversion in riskless and risky choices. CeDEx Discussion Paper Series, (2010-20), 26. https://doi.org/10.1007/s10273-011-1262-2

Haushofer, J., \& Fehr, E. (2014). On the psychology of poverty. Science, Vol. 344, pp. 862-867. https://doi.org/10.1126/science.1232491

Haushofer, J., Schunk, D., \& Fehr, E. (2013). Negative Income Shocks Increase Discount 
Rates. University of Zurich Working Paper.

Kahneman, D. (2011). Thinking, Fast and Slow (Anchor Can). Doubleday Canada.

Kahneman, D., \& Tversky, A. (1979). Prospect Theory: An Analysis of Decision under Risk. Econometrica, 47(2), 263. https:// doi.org/10.2307/1914185

Mani, A., Mullainathan, S., Shafir, E., \& Zhao, J. (2013). Poverty Impedes Cognitive Function. Science, 341(6149), 976-980. https://doi.org/10.1126/science.1238041

Niederle, M., \& Vesterlund, L. (2007). Do women shy away from competition? Do men compete too much? Quarterly Journal of Economics, 122(3), 1067-1101. https://doi.org/10.1162/qjec.122.3.1067

Pammi, V. S. C., Ruiz, S., Lee, S., Noussair, C. N., \& Sitaram, R. (2017). The Effect of Wealth Shocks on Loss Aversion: Behavior and Neural Correlates. Frontiers in Neuroscience, 11. https://doi.org/10.3389/fnins.2017.00237

Rabin, M. (2000). Risk aversion and expected utility: a calibration theorem. Econometrica, 68(5), 1281-1292. https://doi.org/10.1111/1468-0262.00158

Sharkey, P. , Besbris, M., Friedson, M., (2016) Poverty and crime. The Oxford Handbook of the Social Science of Poverty 


\section{Supplementary Information for}

Do Negative Economic Shocks Affect Cognitive Function, Adherence to Social Norms, and Loss Aversion?

Francesco Bogliacino

Corresponding autor

Universidad Nacional de Colombia

Centro de Investigaciones para el Desarrollo (CID)

Felipe Montealegre

Universidad Nacional de Colombia

Centro de Investigaciones para el Desarrollo (CID) 


\section{Table of Contents}

Do Negative Economic Shocks Affect Cognitive Function, Adherence to Social Norms, and Loss

Aversion?

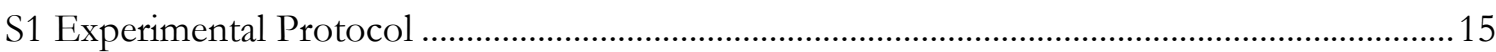

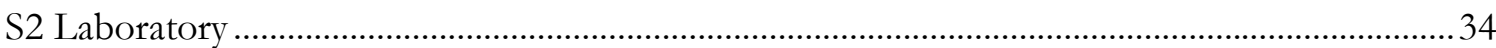

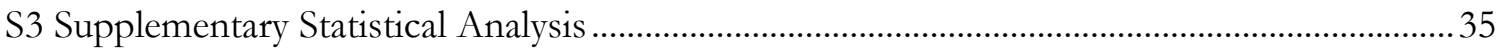

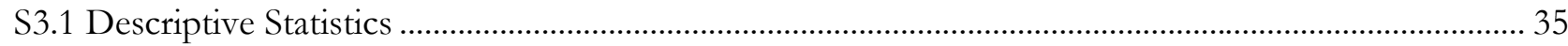

S3.2 OLS Regressions with Robust Standard Errors................................................................................. 37

S3.3 OLS Regressions with Robust Standard Error for Main Effects ............................................................... 42

S3.4 Tests for the Cheating................................................................................................................................ 44

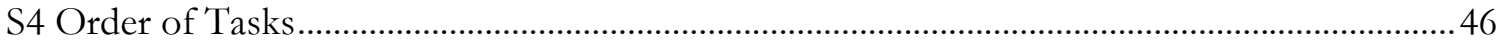

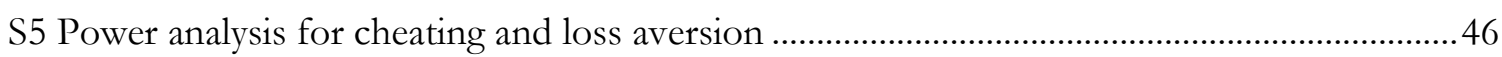

Tables

Table 1: Mean difference with respect to control on standardized and per-task accuracy, response time, and efficiency conditional on a number of exogenous control variables....................................................................

Table 2: Mean difference with respect to control of likelihood of being loss averse, the switching point from

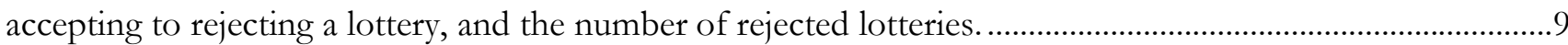

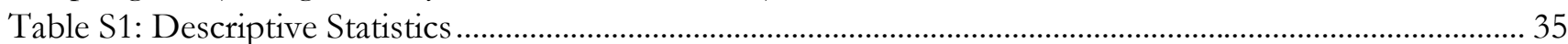

Table S2 T-test of the mean of the control variables by feedback condition...................................................... 35

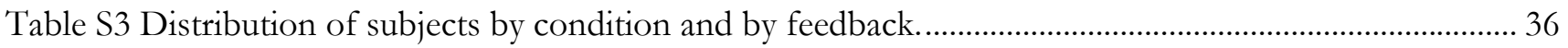

Table S4: Description of Independent Variables Included in Regression Analyses ......................................... 37

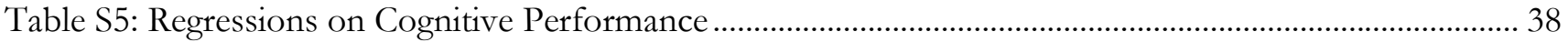

Table S6: Regressions on cognitive performance, controlling for first round of RET.................................... 39

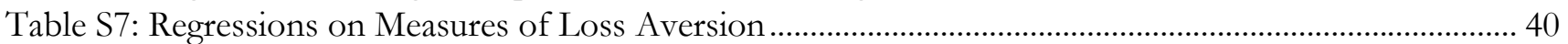

Table S8: Regression on the Likelihood of Reporting 4 or 5 in the Cheating Game........................................ 41

Table S9: Regressions on Cognitive Performance (Main Effects) …………..................................................... 42

Table S10: Regressions on Measures of Loss Aversion (Main Effects) ............................................................. 43

Table S11: Regression on the Likelihood of Reporting 4 or 5 in the Cheating Game (Main Effects) ............ 44

Table S12: $\chi^{2}$ test of distributions between observed and expected frequencies in the Cheating Game ........ 45

Table S13: $\chi^{2}$ Test for Independence between treatments and the Reported Die Roll................................... 45

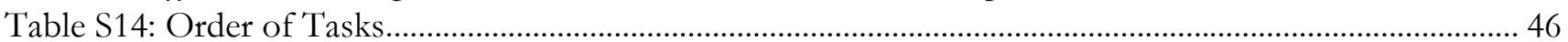

Figures

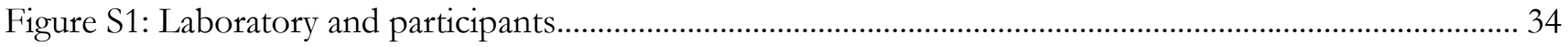




\section{S1 Experimental Protocol}

Note: This is a translation to English from the original protocol in Spanish.

\section{[Before starting the session]}

The information written in square brackets and italics must not be read to participants. These are the procedures to be followed by the experimenter.]

[Turn on computers. Start the session in each of them. Start in kiosk mode. Set up the cardboard divisions for each workstation.]

[Place a blank sheet of paper, a pen, and a die inside a plastic cup, in front of each computer. Open the google chrome shortcut. Check that every computer is connected to the room.]

Before Starting the session, greet the participants and remind them that for them to participate they must have their ID with them. Align them into a line in order of arrival. Only 18 of them can participate in that session. Others are welcomed to participate in the next session. Give access to the lab by two at a time with the ID card. At the control cabin check if any one of them had participated before.]

\section{[General Instructions]}

When the quota of participants is completed for the session or when it is time to start the session ask participants to log in with their university credentials. After everyone has logged in, start the session.]

\section{creating_session}

[Participants will see the following screen while you read aloud the instructions]

\section{Welcome \\ Please do not press the "next" button unless you are instructed to do so. \\ Please pay attention to all of the researcher's instructions.}

\section{Next}

Welcome. We thank you for taking part in this exercise that is part of a study about decision making that we are conducting in Facultad de Ciencias Económicas. It will take approximately 1 hour. From now on it is 
forbidden to communicate with other participants, for any question raise your hand. The use of electronic devices is expressly forbidden. Please be quiet and turn off your cellphones.

\section{[Give them a moment to turn off their cellphones]}

In front of you, there is a blank paper sheet, a pen and a plastic cup with a die inside it. Please do not use them until indicated.

Depending on your decisions, you can win a certain amount of money. Therefore, it is necessary for you to pay attention to these instructions. All information collected for this study is confidential and will be used for academic purposes only. Your name, identification number (ID) or e-mail will not be shown in any document or report about this study.

It is important for you to know that you can walk away; however, only if you complete the exercise and complete the final questionnaire you can receive the amount of money you earned for your decisions. The money used to pay the participants was given by Facultad de Ciencias Económicas and not by the researchers of the study. This is a public entity and, as such, we cannot legalize your payment without collecting a copy of your ID card. We will do this at the end of the session. We apologize if this can be an inconvenience for you.

This exercise comprises two parts. In the first part, you have to solve an addition task. In the second part, you will have to complete four activities, three of which are tasks and one is a decision. That is, this exercise has a total of four tasks and one decision.

Now I will tell you how your earnings are determined. The addition task will always be paid. From the other four remaining activities, only one will be paid. The activity to be paid from the four remaining activities will be drawn by one of you, once all of you will have finished with the activities and after the completion of a very short questionnaire.

In order to do this, each activity has assigned one color: Blue, Green, Yellow, Red. Neither you nor we know which one of the remaining four tasks will be paid until the end of the session when a volunteer will draw one of these colored balls [show the colored balls to everyone] from this black bag [show the black bag to everyone]. It is important for you to think carefully about your decisions because you will only know which of them will be paid once you will have finished everything. To resume, once you will have finished answering all tasks, completed the final questionnaire, and drawn an activity to pay, we will call each one of you, one by one, to give you the earnings from the addition task and the earnings from the task corresponding to the drawn ball.

If you have any questions, please raise your hand and I or any assistant will come by to answer it.

Given this information, we want to confirm that you want to participate in this exercise. If so, click on the "next" button.

[While the participants wait for the other participants to press the button, the following screen appears:] 


\section{Please wait}

Waiting for the other participants.

[When all participants pressed the "next" button the following screen appears with the informed consent:] 


\section{Informed consent}

You have been invited to participate in a study with the objective of understanding how people make decisions. This research is being conducted by Andrés Felipe Montealegre Olaya, under the supervision of Professor Francesco Bogliacino, affiliated to the Facultad de Ciencias Económicas from the Universidad Nacional de Colombia. You must be of legal age to participate in this study; that is, 18 years or over.

If you are willing to participate, you will have four tasks to complete and one decision to make. Additionally, you will have to answer some questions. You will do these activities in a place in which you can feel comfortable to do them. Participation in this activity will take approximately 1 hour of your time.

Your participation is voluntary and you are free to leave at any time. Likewise, if you wish to leave some questions unanswered, please feel free to do so. However, it would be greatly appreciated if you could answer them all.

This study follows the guidelines set by the Colombian Ethical Dispositions in Research, Resolution 8430 (1993), which has established the scientific, technical and administrative regulatory framework for scientific studies that involve the participation of human beings. This research is classified as one in which the participation of human beings is at 'low risk', in that it does not involve risks during or after the research for those who participate. A possible inconvenience associated with the research is the time it takes to complete the activities required.

If there is anything related to this research that you would like clarified, if you wish to inform us of any problems or have questions regarding your rights as a participant or any other aspect of this research, please do not hesitate to contact Professor Francesco Bogliacino (phone number: (57) 316-5000 ext. 12388, e-mail: fbogliacino@unal.edu.co).

By writing your name and your ID number below, you declare that you have been properly informed of the terms of the research and that you participate in this research voluntarily.

Yours faithfully

Andrés Felipe Montealegre Olaya.

First name and last name:

Id number:

\section{[Read out loud the informed consent]}

If you agree to participate in this study, please write your full name and your ID number in the space indicated. Once done, please press the "next" button. After filling out the informed consent please follow the on-screen instructions.

[While participants wait for other participants to fill out the informed consent, they will see the following screen:] 


\section{Please wait}

Waiting for the other participants.

\section{[Instructions. Part 1.]}

\section{[Addition task]}

When participants had filled the informed consent and clicked on the "next" button they will see the instructions for the addition task in the screen:]

\section{Instructions}

This is the first part of the study.

On your computer screen addition problems of five numbers of two digits each will appear, one at a time. These addition problems are randomly generated by the computer. You will have to solve as many problems as you can in two periods of four minutes each. At the end of each period, you will see on the screen your number of correct and incorrect answers. You will accumulate 1,000 points for each correctly solved problem in the first period. At the end of the first period, you can face two events. In the first event, with a probability of $50 \%$ (which is the same probability that when flipping a coin, it will land on heads), you can keep all of the points that you have accumulated for this period or lose half of them. In the second event, with a probability of $50 \%$ (which is the same probability that when flipping a coin, it will land on heads), it may happen that each correctly solved problem in the second period still gives you 1,000 points or just 500 points. This means that you may find yourself in a situation in which you are in either of the two events, in both events, or in neither of the events.

To perform the addition task, if you wish to, you can use the blank sheet of paper in front of you. The better your performance, the higher your earnings in this first task. Accumulated earnings in this task will be paid with certainty at the end of this activity, along with the earnings of the task drawn from amongst the other four tasks of the second part.

For each correct answer in this activity, you will receive 1,000 points. At the end of the exercise, points that constitute your payment will be converted to Colombian pesos. Each point is equivalent to 1 Colombian peso.

When you are ready to start, click on the "next" button.

Next

[Participants start the first round of the addition task until the time runs out. They will see the following screen (note that the numbers here are just an example):] 


\section{Let's add!}

Time left to complete this page: 0:22

$13+90+23+44+2=$

The last round was number: 1.

Your last answer was: correct.

Number of correct answers so far: 1 .

If you answer this question correctly you will earn 1000 points

Accumulated earnings so far: 1000 points

Next

When the time runs out and depending on the experimental treatment the participant was randomly assigned to, they will see the following screen (in this example the experimental treatment is NIS =1, NWS = 1):]

\section{ANNOUNCEMENT}

Your accumulated earnings have been affected. You have lost half of your accumulated earnings.

You had accumulated $\mathbf{1 0 0 0}$ points; now you have $\mathbf{5 0 0}$ points.

Additionally, your payment for each correct answer has been affected.

You were earning 1000 points for each correct answer.

Now, for each correct answer you will earn $\mathbf{5 0 0}$ points.

Next

When they click on the "next" button, the second round of the addition task will start. They will see on the screen a similar screen as in the first round:] 


\section{Let's add!}

Time left to complete this page: 0:06

$11+27+74+92+88=$

The last round was number: 51 .

Your last answer was: correct.

Number of correct answers so far: 1 .

If you answer this question correctly you will earn 500 points

Accumulated earnings so far: 500 points

Next

When the time for the second round of the addition task runs out, they will see a summary of their performance in this task on their screens as in the following screen]

\section{This was your performance in this activity}

\begin{tabular}{cccccc} 
Time left to complete this page: 0:28 & Addends & Solution & $\begin{array}{c}\text { Your } \\
\text { answer }\end{array}$ & $\begin{array}{c}\text { Was it } \\
\text { correct? } \\
1=\text { Yes, } 0 \\
\text { No }\end{array}$ & $\begin{array}{c}\text { Points per correct } \\
\text { answer }\end{array}$ \\
$\begin{array}{c}\text { Addition problem } \\
\text { number }\end{array}$ & $75+84+81+17+23$ & 280 & 280 & 1 & 1000 \\
\hline 1 & $13+90+23+44+2$ & 172 & 240 & 0 & 1000 \\
\hline 2 & $85+20+10+34+91$ & 240 & 240 & 1 & 1000 \\
\hline 51 & $19+27+52+13+43$ & 154 & 363 & 0 & 500 \\
\hline 52 & $11+27+74+92+88$ & 292 & 241 & 0 & 500 \\
\hline 53 & $19+31+21+44+5$ & 120 & 210 & 0 & 500 \\
\hline
\end{tabular}

Next

[When they click on the "next" button, the second part of the exercise will start with the instructions of the first task]

\section{[Instructions. Part 2]}




\section{[STM task $\left(\right.$ Blue $\left.\left.^{2}\right)\right]$}

\section{Instructions}

This is the second part of the study.

In this task, we will show you a set of images during a time period of 30 seconds. You will see 20 images on the screen like this one:

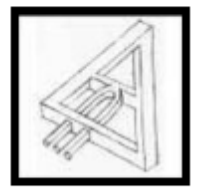

After the 30 seconds, the screen will disappear and then a series of screens will appear; each one showing you three images. Only one of these images will have been included in the previous screen with the 20 initial images. In total, we will show you 20 sets of three images. For each of these sets, we will ask you to select the image that was included in the initial set of 20 images.

For example:

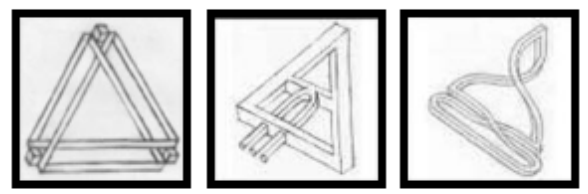

From these three images, you will have to select the one that appeared in the initial set of 20 images. You have 1 minute to answer as many questions as you can.

For each correct answer, you will receive 1 Experimental Currency Unit (ECU). At the end of this exercise, the ECU that constitute your payment will be converted to Colombian pesos. Each ECU is equivalent to 1,000 Colombian pesos.

If you have any questions, please raise your hand and an assistant will approach you.

When you are ready to start, click on the "next" button.

Next

[When they click on the "next" button, the set of 20 images will appear in the following screen:]

${ }^{2}$ Hereafter, we report the activity with the color of the ball used to perform the final draw. 


\section{Memory}

Time left to complete this page: 0:08

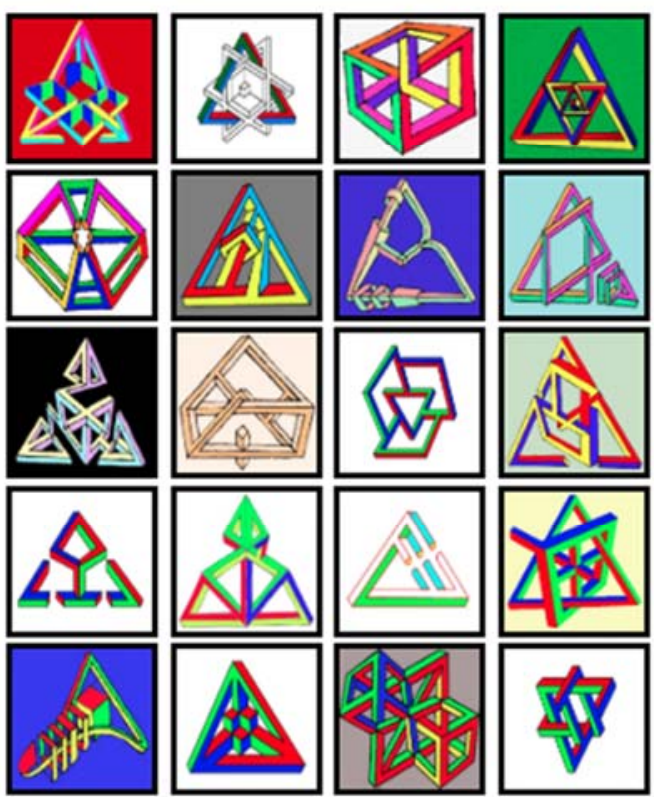

[30 seconds later the last screen will disappear and a succession of 20 pages in which 20 sets of 3 images each is shown to the participant. One set per page. These pages are similar to the next one:]

\section{Memory}

Time left to complete this page: 0:31

Please identify the image that was included in the initial set of 20 images previously showed to you by clicking on it.
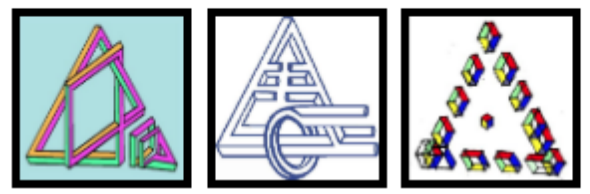

[After the time is up, they will see the following screen]

----> According to the feedback treatment, participants will see the following: <----

----> No-feedback sessions: <---- 
Please click on the "next" button to continue with the next activity.

Next

$--->$ Feedback sessions :<----

\section{Memory}

This was your performance in this activity:

You had a total of 9 correct answers.

Your payoff for this activity is $9 \mathrm{ECU}$.

Please click on the "next" button to continue with the next activity.

Next

$---->$ End of conditional $<----$

[When they click on the "next" button, the second task of the second part starts:]

\section{[FI (Red)]}

\section{Instructions}

This is the second part of the study.

In this task, we will show you 10 exercises. In each of these exercises, you are asked to complete a logical sequence of images. To do so, you will have to choose the missing image from a set of five images. Only one of the options is the correct one. When you click on one of the options, the next exercise will be shown to you. You have 1 minute to solve as many exercises as you can.

For each correct answer, you will receive 1 Experimental Currency Unit (ECU). At the end of this exercise, the ECU that constitute your payment will be converted to Colombian pesos. Each ECU is equivalent to 1,000 Colombian pesos.

If you have any questions, raise your hand and some assistant will approach you to solve it.

When you are ready to start, click on the "next" button.

Next

When they click on the "next" button, participants will see a set of 10 pages. Each page has one problem very similar to the next one:] 


\section{Logic}

Time left to complete this page: 0:44
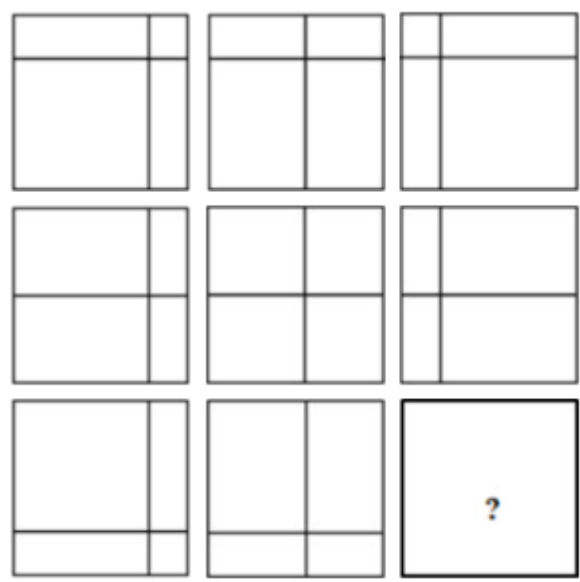

From the options shown below, please indicate which one should replace the question mark in order to complete the sequence. Select it by clicking on it.
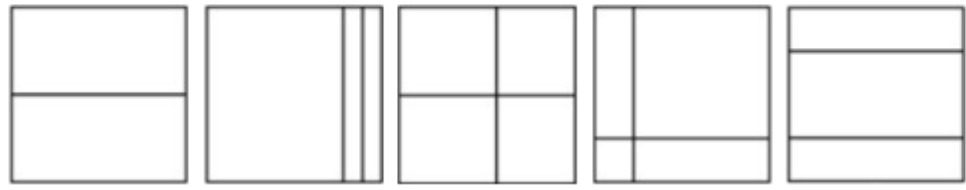

[After time is up, they will see the following screen:]

----> According to the feedback treatment, participants will see the following: <----

----> No-feedback sessions: <----

Please click on the "next" button to continue with the next activity.

Next

---> Feedback sessions :<---- 


\section{Logic}

This was your performance in this activity:

You had a total of 6 correct answers.

Your payoff for this activity is $6 \mathrm{ECU}$.

Please click on the "next" button to continue with the next activity.

Next

$--->>$ End of conditional $<----$

[When they click on the "next" button, the third task of the second part starts:]

\section{[Dice (Green)]}

\section{Instructions}

This is the second part of the study.

In this task, you will determine you own payment by rolling a die on two occasions when you are instructed to do so. Your first throw will determine how much you will receive.

You can see the exact payment in the following table:

\begin{tabular}{rcccccc}
\hline Die roll result & $\mathbf{1}$ & $\mathbf{2}$ & $\mathbf{3}$ & $\mathbf{4}$ & $\mathbf{5}$ & $\mathbf{6}$ \\
\hline Payment in ECU & $2 \mathrm{ECU}$ & $4 \mathrm{ECU}$ & $6 \mathrm{ECU}$ & $8 \mathrm{ECU}$ & $10 \mathrm{ECU}$ & $0 \mathrm{ECU}$
\end{tabular}

This table will remain on the screen until you have typed the value that you have rolled on the die. The purpose of the second roll is only for you to make sure that the die is working properly. You may roll the die more than twice, however, it is only the first roll that counts. Please bear in mind that your roll is completely private. On the following screen you will be asked to make your rolls.

At the end of this exercise, the ECU that constitute your payment will be converted to Colombian pesos. Each ECU is equivalent to 1,000 Colombian pesos.

If you have any questions, raise your hand and some assistant will approach you to solve it.

When you are ready to start, click on the "next" button.

\section{Next}

[When they click on the "next" button, the following screen shows up:] 


\section{Dice}

\begin{tabular}{rcccccc} 
Die roll result & $\mathbf{1}$ & $\mathbf{2}$ & $\mathbf{3}$ & $\mathbf{4}$ & $\mathbf{5}$ \\
\hline Payment in ECU & $2 \mathrm{ECU}$ & $4 \mathrm{ECU}$ & $6 \mathrm{ECU}$ & $8 \mathrm{ECU}$ & $10 \mathrm{ECU}$
\end{tabular}

Please take the die in front of you and roll it.

Please select the number you rolled on the first try from the list below:

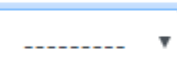

Now select the payment according to the table above from the list below:

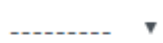

When you have completed the rolls, please press the "next" button.

Next

Only when they have rolled the die, reported the number, and selected the related payoff, they can click on the "next" button. The following screen is displayed:]

---> According to the feedback treatment, participants will see the following: <----

----> No-feedback sessions: <----

Please click on the "next" button to continue with the next activity.

Next

---> Feedback sessions :<---- 


\section{Dice}

This was your performance in this activity:

You reported having rolled number 5 .

Your payoff for this activity is $10 \mathrm{ECU}$.

Please click on the "next" button to continue with the next activity.

Next

$---->$ End of conditional $<----$

[When they click on the "next" button, the fourth task of the second part starts:]

\section{[Lottery (Yellow)]}

\section{Lottery}

This is the second part of the study.

For this exercise, you have been assigned 7 Experimental Currency Units (ECU). The payment for this activity will depend solely on this endowment and your decisions in this activity.

In the following, we will ask you to make a series of decisions based on two options. For each of the rows in the table below you have to make a choice between two options. Option 1 is a lottery. A lottery is like throwing a coin. If it comes up heads ( $50 \%$ probability) you will earn more ECU. If it comes up tails ( $50 \%$ probability), you will lose some ECU. Option 2, on the contrary, is not going to make you win or lose any additional ECU.

At the end, the computer will randomly pick one of the 6 rows and will make your choice for that row effective; that is, if you chose option 1, you will receive the initial endowment plus the result from the lottery. If you chose option 2, you will receive the initial endowment only.

Let us look at an example:

If the computer picks the first row to make your choice effective and, additionally, you decide to play that lottery, you may lose 2 ECU with a probability of $50 \%$, or, you may win 6 ECU more with a probability of $50 \%$. If you decide not to play, you will not win or lose any additional ECU.

At the end of this exercise, the ECU that constitute your payment will be converted to Colombian pesos. Each ECU is equivalent to 1,000 Colombian pesos.

If you have any questions, please raise your hand and an assistant will approach you. 
If you have any questions, please raise your hand and an assistant will approach you.

\begin{tabular}{|c|c|c|c|c|c|}
\hline \multirow[t]{2}{*}{ Row number } & \multicolumn{2}{|c|}{ Option 1} & \multirow{2}{*}{$\begin{array}{c}\text { Option } 2 \\
100 \%\end{array}$} & \multicolumn{2}{|c|}{ Choose between Option 1 or Option 2} \\
\hline & $50 \%$ & $50 \%$ & & Option 1 & Option 2 \\
\hline 1 & Lose 2 ECU & Win 6 ECU & OECU & $\mathrm{O}$ & $\bigcirc$ \\
\hline 2 & Lose 3 ECU & Win $6 \mathrm{ECU}$ & OECU & 0 & 0 \\
\hline 3 & Lose 4 ECU & Win $6 \mathrm{ECU}$ & OECU & 0 & O \\
\hline 4 & Lose 5 ECU & Win $6 \mathrm{ECU}$ & O ECU & 0 & $\bigcirc$ \\
\hline 5 & Lose 6 ECU & Win $6 \mathrm{ECU}$ & OECU & 0 & 0 \\
\hline 6 & Lose 7 ECU & Win $6 \mathrm{ECU}$ & O ECU & $\mathrm{O}$ & $\mathrm{O}$ \\
\hline
\end{tabular}

Next

[When they click on the "next" button, a summary of the results in this task is displayed to participants:]

\section{Results}

The computer picked lottery $\mathbf{5}$ for payment.

Your payment for this decision is 1 ECU.

Next

When they click on the "next" button, a waiting screen will be shown to them where they are informed to wait for the other participants to start the draw of the task to be pay from the tasks in the second part of the experiment:]

\section{Please wait}

Please wait for the other participants to start the draw of the activity to pay from the second part of the exercise.

\section{[Draw of the experimental task to pay for the second part]}


When all participants have reached the waiting page, the process of drawing out the task to be paid from the tasks of the second part is started. In this screen, participants are shown how many points they earned in the addition task and how many ECU they earned in each of the other tasks. The following instructions appear onscreen:]

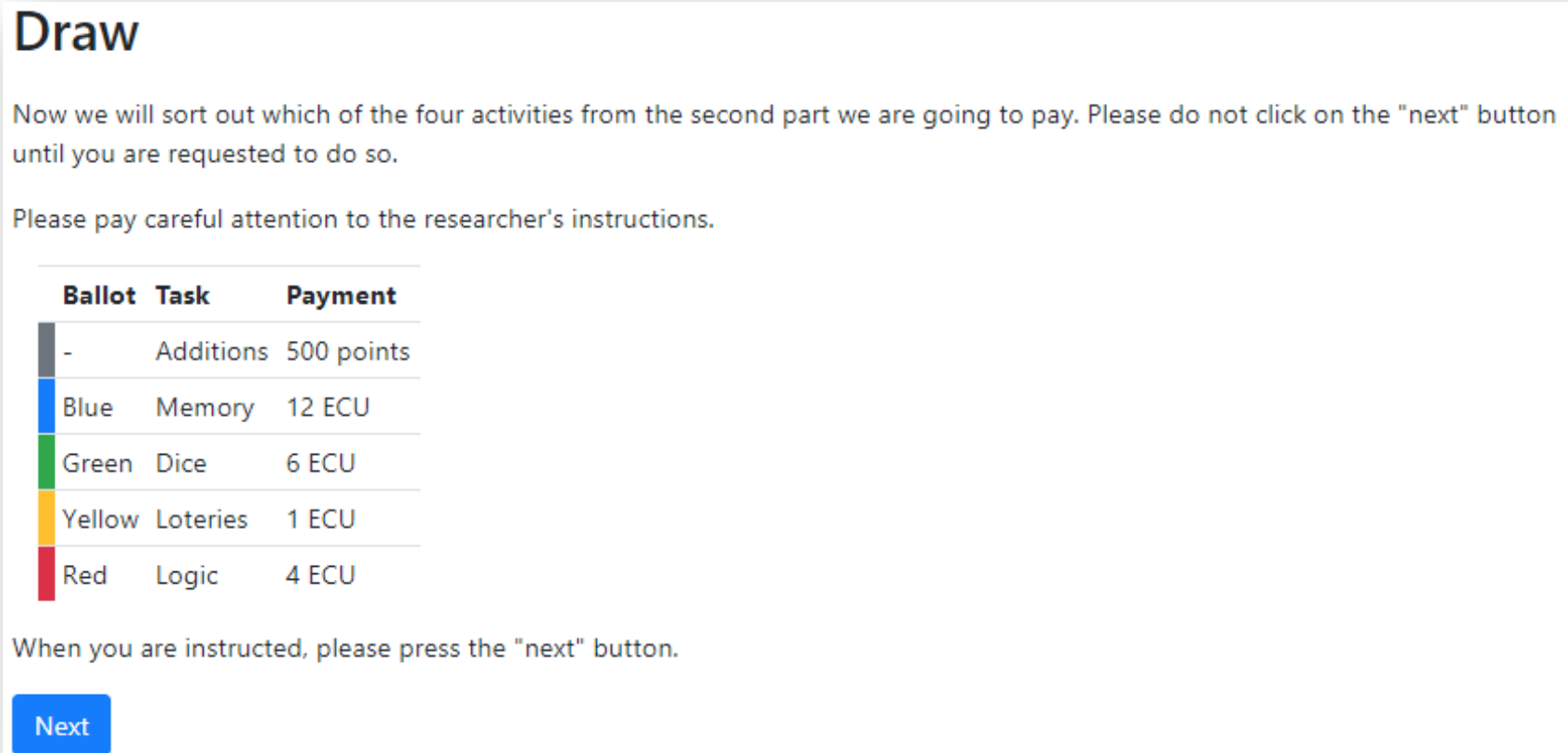

Now we will draw the task to be paid from the four tasks of the second part. Remember that the addition task will always be paid. For this, we will use this black bag [show the black bag to everyone again] and these ballots [show the colored ballots again]. If the blue ball is drawn, then the memory task is the one to be paid. If the green ball is drawn, then the die task will be paid. If the yellow ballot is drawn, then the lottery decision is to be paid. If the red ball is drawn, then the logic task will be paid.

Please one volunteer among you step forward to make the draw. [Inform the volunteer she is not allowed to look into the black bag. The draw is made]

[Say this while showing the ball to everyone] The draw ballot was the [color] one, therefore, the task to be paid is the [task name accordingly].

Now we will calculate your earnings. While we do so please answer the questionnaire that is on the following screen. We will call you one by one to deliver your payment inside an envelope and register your id card. Please click on the "next" button.

[When all participants had clicked on the "next" button, in the following screen appears the questionnaire page]

\section{[Questionnaire]}




\section{Questionnaire}

Now we are calculating your payment. While we do so, please fill in the following questionnaire.

What is your sex?

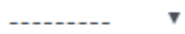

How old are you?

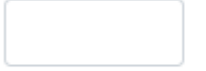

What is your marital status?

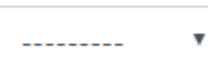

What is your current undergraduate program?

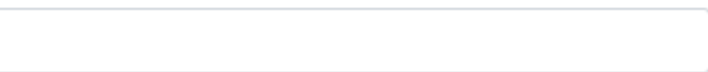

How many semesters have you paid, including the current one?

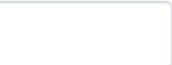

What is your father's maximum degree of education?

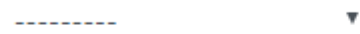

What is your mother's maximum degree of education?

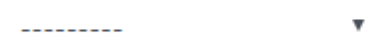

According to your utility bills, what is the Socioeconomic Stratum (SES) of the dwelling you currently live in?

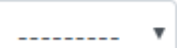

What is the approximate salary you earn in Monthly Legal Minimum Wages (SMMLV)?

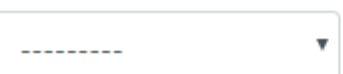


In which urban district do you live in?

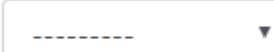

What is your weight in Kilograms?

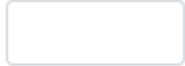

What is your height in centimeters?

How do you consider yourself? Normally, are you a person totally willing to take risks or do you try to avoid taking risks? Please answer using the following scale from 1 to 5 , where 1 means "totally willing to take risks" and 5 means "totally averse to take risks".

Totally willing to take risks

$0_{1}$

2

3

${ }_{4}$

5

Totally averse to take risks

How do you consider yourself? Normally, are you a person totally willing to take risks of a financial nature or do you try to avoid taking risks of financial nature? Please answer using the following scale from 1 to 5 , where 1 means "totally willing to take risks" and 5 means "totally averse to take risks".

Totally willing to take risks

$\bigcirc_{1} \bigcirc_{2}$

3

$\mathrm{C}_{4}$

5

Totally averse to take risks

If you need to find $\$ 600,000$ in one week to cover an unexpected expenditure, how much difficulty would there be in getting the money?

I will not have any difficulty.

I will have some difficulty, but will get it.

I do not know if I will get it.

Definitely, I will not get it.

\section{Next}

\section{[Payment procedure]}

While participants answer the questionnaire, the session assistant hands out a receipt of payment (compulsory under university regulations) for participants to fill out]

[After completing the questionnaire, participants click on the "next" button and see and instruction to please remain sited until they are asked to come to the front desk as in the following screen:] 


\section{The end}

We thank you for your participation in this research.

Please remain sited in your seat. we will call you by your name to hand you over the envelope with your payment. Please bring the pen and the die. After this you can step out of the room.

If you wish to participate in an activity similar to this in which you can also earn some money, please write your e-mail for us to reach to you later.

E-mail:

Have a good day.

\section{Next}

[After delivering the envelopes, check if the form has been filled correctly. Thank the participant and ask her to leave the room. $]$ 


\section{S2 Laboratory}

Figure S1: Laboratory and participants
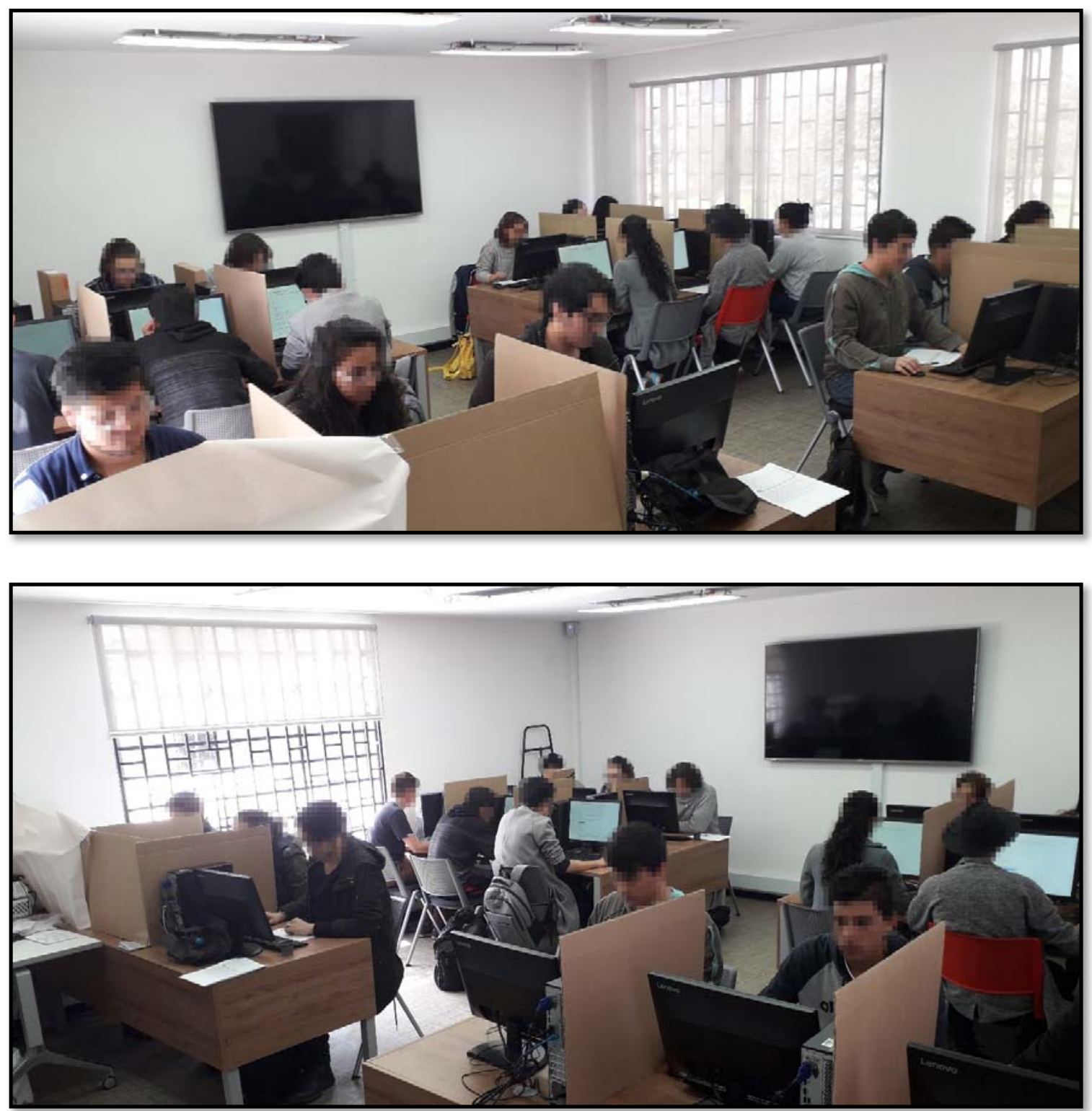


\title{
S3 Supplementary Statistical Analysis
}

\author{
S3.1 Descriptive Statistics
}

Table S1: Descriptive Statistics

\begin{tabular}{|c|c|c|c|c|c|c|c|}
\hline Variable & Mean & Mode & $\%$ & Second most frequent & $\%$ & Minimum & Maximum \\
\hline Sex & - & Male & $(63.93 \%)$ & - & - & 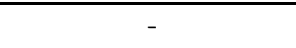 & 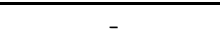 \\
\hline Age & 21.69 & $20 \mathrm{y} / \mathrm{o}$ & $(16.46 \%)$ & $18 \mathrm{y} / \mathrm{o}$ & $(15.71 \%)$ & 18 & 42 \\
\hline Civil State & - & Single & $(97.14 \%)$ & - & - & - & - \\
\hline \multirow[t]{2}{*}{ Academic Program } & - & Graphic Design & $(8.21 \%)$ & Business Management & $(6.79 \%)$ & - & - \\
\hline & & - & - & Psychology & $(6.79 \%)$ & - & - \\
\hline Math Training & - & $\mathrm{Si}$ & $(41.13 \%)$ & - & - & - & - \\
\hline Semesters & 6.08 & 3 & $(16.43 \%)$ & 6 & $(11.79 \%)$ & 1 & 15 \\
\hline Mother's Education & - & College & $(27.50 \%)$ & Undergraduate & $(25.00 \%)$ & - & - \\
\hline Father's Education & - & College & $(23.21 \%)$ & College & $(22.14 \%)$ & - & - \\
\hline Municipal District & - & Suba & $(16.07 \%)$ & Teusaquillo & $(14.29 \%)$ & - & - \\
\hline Income (MLMW) & - & $<1$ MLMW & $(68.10 \%)$ & 1-2 MLMW & $(19.71 \%)$ & $<1$ MLMW & $>7$ MLMW \\
\hline SES & & 3 & $(46.43 \%)$ & 2 & $(29.29 \%)$ & 1 & 5 \\
\hline BMI & & Normal & $(74.91 \%)$ & Overweight & $(13.62 \%)$ & Severely Underweight & Morbid Obesity \\
\hline Risk Propensity & & 2 & $(37.14 \%)$ & 3 & $(35.36 \%)$ & 1 & 5 \\
\hline Financial Risk Prope & ensity & 3 & $(35.36 \%)$ & 4 & $(29.29 \%)$ & 1 & 5 \\
\hline Emergency & & 3 & $(54.64 \%)$ & 2 & $(34.29 \%)$ & 1 & 4 \\
\hline $\begin{array}{l}\text { Losses (share of } \\
\text { average } \\
\text { experimental } \\
\text { earning) }\end{array}$ & $15.65 \%$ & $\mathrm{SD}(13.50 \%)$ & - & - & - & $0 \%$ & $100 \%$ \\
\hline
\end{tabular}

MLMW stands for minimum legal monthly wage. In Colombia, by the time of the experiment the MLMW was around 781.242 COP. By the time the experiment was conducted 1 USD was equal to 2958.57 COP. SES stands for Socio-Economical Stratum. SES and Math training is explained in detail in Table S4 below. BMI stands for Body Mass Index. Risk propensity, Financial Risk Propensity, are standard validated scales. Emergency is a question on how easy would be to face an unexpected large expenditure (from 1-4). Losses is calculated as the share of losses in the RET to the average experimental earning. SD stands for standard deviation.

Since we randomize by session the presence of feedback, we report also the t-test for the main control variables by feedback, controlling for unequal variances. Apart for age, there is no significant difference, as it would be expected since we were randomizing.

Table S2: T-test of the mean of the control variables by feedback condition.

\begin{tabular}{cc}
\hline Variable & p-value \\
\hline Order & 0.0687 \\
Female $=1$ & 0.1994 \\
Age & 0.0275 \\
Math related & 0.7386 \\
SES (3-4) & 0.3742 \\
SES (5-6) & 0.1589 \\
Emergency & 0.6648 \\
Joint F test: $\mathrm{F}(6,268)=1.39, \mathrm{p}=0.217$ \\
\hline
\end{tabular}

We also report the distribution of the subjects by feedback and by experimental treatments. 
Table S3: Distribution of subjects by condition and by feedback.

\begin{tabular}{cccc}
\hline & \multicolumn{3}{c}{ Feedback } \\
Condition & No & Yes & Total \\
\hline Control & 17 & 59 & 76 \\
NIS Only & 15 & 57 & 72 \\
NWS Only & 20 & 49 & 69 \\
NWS \& NIS & 18 & 47 & 65 \\
Total & 70 & 212 & 282 \\
\hline
\end{tabular}


In all regressions, the estimated model is the following:

$$
\begin{aligned}
Y_{i} & =\beta_{0}+\beta_{1} T 2_{i}+\beta_{2} T 3_{i}+\beta_{3} T 4_{i}+\gamma_{0} \text { FEED }_{i}+\gamma_{1} \text { Order }_{i}+\gamma_{2} \text { Order }_{i}+\gamma_{3} \text { Order }_{i} \\
& +\gamma_{4} \text { Order }_{i}+\gamma_{5} \text { Order }_{i}+\gamma_{6} \text { Age }_{i}+\gamma_{7} \text { Female }_{i}+\gamma_{8} \text { Math }_{i}+\gamma_{9} \text { SES } 3-4_{i} \\
& +\gamma_{10} \text { SES } 5-6_{i}+\gamma_{11} \text { Emergency }_{i}+\varepsilon_{i}
\end{aligned}
$$

Where $\mathrm{Y}$ is the outcome variable, $i$ is the index for subject, and all regressors are included and explained

\begin{tabular}{|c|c|}
\hline Variables & Definition \\
\hline $\mathrm{T} 2$ & $\begin{array}{l}\text { A dummy variable that equals to } 1 \text { if the participant was assigned to the second treatment (NIS only) and } 0 \\
\text { otherwise. }\end{array}$ \\
\hline T3 & $\begin{array}{l}\text { A dummy variable that equals to } 1 \text { if the participant was assigned to the third treatment (NWS only) and } 0 \\
\text { otherwise. }\end{array}$ \\
\hline $\mathrm{T} 4$ & $\begin{array}{l}\text { A dummy variable that equals to } 1 \text { if the participant was assigned to the fourth treatment (Both NIS and } \\
\text { NWS) and } 0 \text { otherwise. }\end{array}$ \\
\hline Feedback & $\begin{array}{l}\text { A dummy variable that is equal to } 1 \text { if participants were shown feedback on their performance on the four } \\
\text { tasks of the second part (STM, FI, cheating, LA), } 0 \text { otherwise. }\end{array}$ \\
\hline Order 2 & $\begin{array}{l}\text { To control for order effects in the task we randomly assigned participants to one of each of the six possible } \\
\text { orders as depicted in Table S14. A dummy variable that is equal to one if participants were shown the tasks } \\
\text { in the second order. } 0 \text { otherwise. }\end{array}$ \\
\hline Order 3 & A dummy variable that is equal to one if participants were shown the tasks in the third order. 0 otherwise. \\
\hline Order 4 & A dummy variable that is equal to one if participants were shown the tasks in the fourth order. 0 otherwise. \\
\hline Order 5 & A dummy variable that is equal to one if participants were shown the tasks in the fifth order. 0 otherwise. \\
\hline Order 6 & A dummy variable that is equal to one if participants were shown the tasks in the sixth order. 0 otherwise. \\
\hline Age & It depicts the age of the participant. \\
\hline Female $=1$ & A dummy that is equal to 1 if the participant was a female. 0 otherwise. \\
\hline Math related & $\begin{array}{l}\text { A dummy variable that is equal to } 1 \text { if the academic program has strong training in mathematics. } 0 \text { otherwise. } \\
\text { Among all the academic programs participants were enrolled to, those with strong training in mathematics } \\
\text { are all the engineering programs, mathematics, physics, economics, statistics, chemistry and biology. Those } \\
\text { without strong math training were business management, anthropology, architecture, plastic arts, political } \\
\text { science, cinema and television, public accounting, law, graphical design, nursing, literary studies, pharmacy, } \\
\text { philology and languages, philosophy, history, linguistics, medicine, veterinary medicine, dentistry, } \\
\text { psychology, sociology, social work, and zoology. }\end{array}$ \\
\hline SES (3-4) & $\begin{array}{l}\text { Socio-economic stratum (SES) is obtained from participant's self-reported utility-bills dwelling classification. } \\
\text { In Colombia, SES is a dwelling classification used to charge for utility bills in a differentiated way (subsidies } \\
\text { and contributions). Dwelling classification depends on its physical characteristics, its geographical } \\
\text { environment, among other things. SES is divided into } 6 \text { tiers. Tier } 1 \text { (6) is the lowest (highest) tier. We split } \\
\text { participants into three categories depending on their SES. Low SES (SES 1-2), medium SES (SES 3-4), and } \\
\text { high SES (SES 5-6). SES (3-4) is a dummy variable that is equal to one if participants reported a SES of } 3 \text { or } \\
4 \text { for their dwelling. } 0 \text { otherwise. }\end{array}$ \\
\hline SES (5-6) & A dummy variable that is equal to one if participants reported a SES of 5 or 6 for their dwelling. 0 otherwise. \\
\hline Emergency & $\begin{array}{l}\text { A standard question used as a proxy of the participants financial situation. See "If you need to find } 600000 \\
\text { COP in a week, to cover an unexpected expenditure, how difficult would it be to get the money? (a) I will } \\
\text { not have any difficulty. (b) I will have some difficulty but will get it. (c) I do not know if I will get it. (d) } \\
\text { Definitely, I will not get it. }\end{array}$ \\
\hline
\end{tabular}
in Table $\mathrm{S} 4$ below.

Table S4: Description of Independent Variables Included in Regression Analyses 
Table S5: Regressions on Cognitive Performance

\begin{tabular}{|c|c|c|c|c|c|c|c|c|}
\hline & & \multicolumn{6}{|c|}{ Accuracy } & \multirow{2}{*}{$\begin{array}{c}\text { Response } \\
\text { Time } \\
\text { Cognitive } \\
\text { Index }\end{array}$} \\
\hline & $\begin{array}{l}\text { Cognitive } \\
\text { Index }\end{array}$ & STM-FI & $\begin{array}{c}\text { F. } \\
\text { Component }\end{array}$ & $\begin{array}{l}\text { RET (first } \\
\text { round) }\end{array}$ & $\begin{array}{l}\text { RET (second } \\
\text { round) }\end{array}$ & STM & FI & \\
\hline Variables & (1) & (2) & (3) & (4) & (4) & (5) & (6) & $(7)$ \\
\hline \multirow[t]{2}{*}{$\mathrm{T} 2$} & -0.084 & -0.035 & -1.878 & -0.205 & -0.427 & 0.217 & -0.179 & 0.097 \\
\hline & $(0.094)$ & $(0.114)$ & $(2.755)$ & $(0.391)$ & $(0.389)$ & $(0.478)$ & $(0.196)$ & $(0.090)$ \\
\hline \multirow[t]{2}{*}{$\mathrm{T} 3$} & $-0.247 * * *$ & $-0.216^{*}$ & $-6.118^{* *}$ & -0.305 & $-0.721 *$ & -0.440 & $-0.348^{*}$ & $0.163^{*}$ \\
\hline & $(0.094)$ & $(0.116)$ & $(2.836)$ & $(0.355)$ & $(0.380)$ & $(0.476)$ & $(0.207)$ & $(0.094)$ \\
\hline \multirow[t]{2}{*}{$\mathrm{T} 4$} & $-0.182^{*}$ & $-0.207^{*}$ & $-4.684^{*}$ & -0.164 & -0.305 & $-1.054^{* *}$ & -0.066 & $0.240 * *$ \\
\hline & $(0.095)$ & $(0.115)$ & $(2.722)$ & $(0.378)$ & $(0.393)$ & $(0.466)$ & $(0.204)$ & $(0.097)$ \\
\hline \multirow[t]{2}{*}{ Feedback } & $0.180^{* *}$ & $0.280 * * *$ & $5.346^{* *}$ & -0.089 & -0.051 & $0.815^{*}$ & $0.348^{*}$ & $-0.216^{* *}$ \\
\hline & $(0.082)$ & $(0.104)$ & $(2.477)$ & $(0.306)$ & $(0.310)$ & $(0.430)$ & $(0.181)$ & $(0.087)$ \\
\hline \multirow[t]{2}{*}{ Order 2} & 0.116 & 0.092 & 2.670 & 0.309 & 0.381 & 0.559 & -0.010 & -0.061 \\
\hline & $(0.109)$ & $(0.135)$ & (3.163) & (0.411) & $(0.441)$ & $(0.587)$ & $(0.219)$ & (0.107) \\
\hline \multirow[t]{2}{*}{ Order 3} & 0.035 & 0.049 & 0.866 & 0.017 & 0.018 & 0.596 & -0.130 & -0.040 \\
\hline & $(0.105)$ & $(0.130)$ & (3.261) & $(0.412)$ & $(0.420)$ & $(0.542)$ & $(0.228)$ & $(0.106)$ \\
\hline \multirow[t]{2}{*}{ Order 4} & $-0.281 * *$ & $-0.348 * *$ & $-7.683^{*}$ & -0.305 & -0.344 & -0.987 & -0.442 & 0.206 \\
\hline & $(0.137)$ & $(0.169)$ & $(3.978)$ & $(0.479)$ & $(0.564)$ & $(0.719)$ & $(0.294)$ & $(0.141)$ \\
\hline \multirow[t]{2}{*}{ Order 5} & 0.122 & 0.161 & 3.454 & 0.488 & 0.099 & 0.314 & 0.266 & -0.021 \\
\hline & $(0.139)$ & $(0.169)$ & (4.074) & $(0.565)$ & $(0.566)$ & $(0.699)$ & $(0.295)$ & $(0.128)$ \\
\hline \multirow[t]{2}{*}{ Order 6} & 0.020 & 0.071 & 0.786 & -0.110 & -0.190 & 0.590 & -0.073 & 0.074 \\
\hline & $(0.107)$ & $(0.138)$ & $(3.297)$ & $(0.366)$ & $(0.382)$ & $(0.597)$ & $(0.226)$ & $(0.116)$ \\
\hline \multirow[t]{2}{*}{ Female $=1$} & $-0.142^{* *}$ & $-0.224 * *$ & $-4.306^{* *}$ & -0.011 & 0.054 & -0.464 & $-0.358^{* *}$ & $0.175^{* *}$ \\
\hline & $(0.072)$ & $(0.088)$ & $(2.099)$ & $(0.286)$ & $(0.300)$ & $(0.369)$ & $(0.153)$ & $(0.075)$ \\
\hline \multirow[t]{2}{*}{ Age } & -0.005 & -0.010 & -0.172 & 0.013 & 0.011 & -0.012 & -0.019 & 0.011 \\
\hline & $(0.012)$ & $(0.014)$ & $(0.391)$ & $(0.046)$ & $(0.048)$ & $(0.056)$ & $(0.028)$ & $(0.011)$ \\
\hline \multirow[t]{2}{*}{ Math related } & $0.243^{* * *}$ & $0.142^{*}$ & $5.502 * *$ & $0.873^{* * *}$ & $1.037 * * *$ & 0.135 & $0.293^{*}$ & $-0.216^{* * *}$ \\
\hline & $(0.071)$ & $(0.086)$ & $(2.142)$ & $(0.286)$ & $(0.292)$ & $(0.353)$ & $(0.151)$ & $(0.071)$ \\
\hline \multirow[t]{2}{*}{ SES (3-4) } & $0.150 * *$ & $0.174^{*}$ & $4.065^{*}$ & 0.026 & 0.236 & 0.308 & $0.300^{*}$ & $-0.142 *$ \\
\hline & $(0.075)$ & $(0.089)$ & (2.203) & $(0.310)$ & $(0.318)$ & $(0.365)$ & $(0.159)$ & $(0.074)$ \\
\hline \multirow[t]{2}{*}{ SES (5-6) } & $0.784 * * *$ & $0.839 * * *$ & $20.444 * * *$ & $1.718^{* * *}$ & $1.574 * *$ & $2.312^{* * *}$ & $1.096 * *$ & $-0.512^{* * *}$ \\
\hline & $(0.185)$ & $(0.235)$ & (4.694) & $(0.623)$ & $(0.729)$ & $(0.818)$ & $(0.470)$ & $(0.152)$ \\
\hline \multirow[t]{2}{*}{ Emergency } & -0.078 & $-0.110^{*}$ & -2.251 & 0.031 & -0.029 & -0.251 & -0.167 & 0.024 \\
\hline & $(0.055)$ & $(0.066)$ & (1.504) & $(0.222)$ & $(0.241)$ & $(0.271)$ & $(0.115)$ & $(0.051)$ \\
\hline \multirow[t]{2}{*}{ Constant } & 0.111 & 0.258 & $50.574 * * *$ & $5.201 * * *$ & $5.599 * * *$ & $13.691 * * *$ & $4.504^{* * *}$ & -0.138 \\
\hline & $(0.315)$ & $(0.389)$ & $(9.979)$ & $(1.187)$ & $(1.231)$ & $(1.572)$ & $(0.709)$ & $(0.314)$ \\
\hline \multirow{2}{*}{$\begin{array}{c}\text { Number of } \\
\text { observations } \\
\text { R-squared }\end{array}$} & 840 & 560 & 280 & 280 & 280 & 280 & 280 & 840 \\
\hline & 0.071 & 0.090 & 0.156 & 0.073 & 0.084 & 0.101 & 0.118 & 0.057 \\
\hline
\end{tabular}

Table S5 reports the results of regressing different measures of cognitive performance on exposure to shocks and a series of individual control variables (Variables are defined in Table S4). Estimators of standardized measures can be interpreted as percentage of standard deviations. Column (1) shows standardized accuracy grouping together the RET, STM and FI tasks into one single measure. Column (2) repeats the analysis excluding the RET. Column (3) shows accuracy results when we pool data using the first component from a Principal Component Analysis. Columns (4) to (6) show accuracy in the RET, STM and FI tasks individually. Column (7) shows the standardized response time it took participants to answer a question on average, irrespectively if the answer was correct or not. This measure groups together the RET, STM and FI tasks into one single measure. Robust standard Errors in parenthesis; *** $\mathrm{p}<0.01, * * \mathrm{p}<0.05,{ }^{*} \mathrm{p}<0.1$. 
Table S6: Regressions on cognitive performance, controlling for first round of RET.

\begin{tabular}{|c|c|c|c|c|c|c|c|c|}
\hline & & \multicolumn{6}{|c|}{ Accuracy } & \multirow{2}{*}{$\begin{array}{c}\text { Response } \\
\text { Time } \\
\text { Cognitive }\end{array}$} \\
\hline & $\begin{array}{l}\text { Cognitive } \\
\text { Index }\end{array}$ & STM-FI & $\begin{array}{c}\mathrm{F} . \\
\text { Component }\end{array}$ & $\begin{array}{l}\text { RET (first } \\
\text { round) }\end{array}$ & $\begin{array}{l}\text { RET (second } \\
\text { round) }\end{array}$ & STM & FI & \\
\hline Variables & $(1)$ & $(2)$ & (3) & $(4)$ & $(5)$ & (6) & $(7)$ & $(8)$ \\
\hline $\mathrm{T} 2$ & $\begin{array}{l}-0.059 \\
(0.090)\end{array}$ & $\begin{array}{l}-0.026 \\
(0.114)\end{array}$ & $\begin{array}{l}-1.357 \\
(2.565)\end{array}$ & $\begin{array}{l}-0.205 \\
(0.391)\end{array}$ & $\begin{array}{l}-0.290 \\
(0.263)\end{array}$ & $\begin{array}{c}0.239 \\
(0.477)\end{array}$ & $\begin{array}{l}-0.166 \\
(0.196)\end{array}$ & $\begin{array}{c}0.068 \\
(0.085)\end{array}$ \\
\hline T3 & $\begin{array}{c}-0.209 * * \\
(0.092)\end{array}$ & $\begin{array}{c}-0.203^{*} \\
(0.116)\end{array}$ & $\begin{array}{c}-5.341 * * \\
(2.710)\end{array}$ & $\begin{array}{l}-0.305 \\
(0.355)\end{array}$ & $\begin{array}{l}-0.516^{*} \\
(0.304)\end{array}$ & $\begin{array}{l}-0.407 \\
(0.475)\end{array}$ & $\begin{array}{l}-0.329 \\
(0.209)\end{array}$ & $\begin{array}{c}0.120 \\
(0.089)\end{array}$ \\
\hline $\mathrm{T} 4$ & $\begin{array}{c}-0.161^{*} \\
(0.092)\end{array}$ & $\begin{array}{c}-0.200^{*} \\
(0.115)\end{array}$ & $\begin{array}{l}-4.267 \\
(2.588)\end{array}$ & $\begin{array}{l}-0.164 \\
(0.378)\end{array}$ & $\begin{array}{l}-0.196 \\
(0.308)\end{array}$ & $\begin{array}{c}-1.037 * * \\
(0.471)\end{array}$ & $\begin{array}{l}-0.057 \\
(0.202)\end{array}$ & $\begin{array}{c}0.217 * * \\
(0.093)\end{array}$ \\
\hline Feedback & $\begin{array}{c}0.191 * * \\
(0.079)\end{array}$ & $\begin{array}{c}0.284^{* * *} \\
(0.103)\end{array}$ & $\begin{array}{l}5.572^{* *} \\
(2.327)\end{array}$ & $\begin{array}{l}-0.089 \\
(0.306)\end{array}$ & $\begin{array}{c}0.008 \\
(0.257)\end{array}$ & $\begin{array}{l}0.824^{*} \\
(0.428)\end{array}$ & $\begin{array}{c}0.353^{* *} \\
(0.179)\end{array}$ & $\begin{array}{c}-0.228 * * * \\
(0.084)\end{array}$ \\
\hline Order 2 & $\begin{array}{c}0.077 \\
(0.105)\end{array}$ & $\begin{array}{c}0.078 \\
(0.134)\end{array}$ & $\begin{array}{c}1.883 \\
(2.940)\end{array}$ & $\begin{array}{l}0.309 \\
(0.411)\end{array}$ & $\begin{array}{c}0.174 \\
(0.364)\end{array}$ & $\begin{array}{l}0.526 \\
(0.585)\end{array}$ & $\begin{array}{l}-0.029 \\
(0.217)\end{array}$ & $\begin{array}{l}-0.018 \\
(0.101)\end{array}$ \\
\hline Order 3 & $\begin{array}{l}0.033 \\
(0.101)\end{array}$ & $\begin{array}{c}0.049 \\
(0.128)\end{array}$ & $\begin{array}{c}0.823 \\
(3.016)\end{array}$ & $\begin{array}{c}0.017 \\
(0.412)\end{array}$ & $\begin{array}{l}0.006 \\
(0.342)\end{array}$ & $\begin{array}{c}0.594 \\
(0.542)\end{array}$ & $\begin{array}{l}-0.131 \\
(0.223)\end{array}$ & $\begin{array}{l}-0.038 \\
(0.100)\end{array}$ \\
\hline Order 4 & $\begin{array}{c}-0.243^{*} \\
(0.136)\end{array}$ & $\begin{array}{c}-0.335^{*} \\
(0.171)\end{array}$ & $\begin{array}{l}-6.905^{*} \\
(3.965)\end{array}$ & $\begin{array}{l}-0.305 \\
(0.479)\end{array}$ & $\begin{array}{l}-0.140 \\
(0.455)\end{array}$ & $\begin{array}{l}-0.954 \\
(0.729)\end{array}$ & $\begin{array}{l}-0.424 \\
(0.296)\end{array}$ & $\begin{array}{c}0.164 \\
(0.136)\end{array}$ \\
\hline Order 5 & $\begin{array}{c}0.061 \\
(0.134)\end{array}$ & $\begin{array}{c}0.140 \\
(0.169)\end{array}$ & $\begin{array}{l}2.211 \\
(3.906)\end{array}$ & $\begin{array}{c}0.488 \\
(0.565)\end{array}$ & $\begin{array}{l}-0.227 \\
(0.403)\end{array}$ & $\begin{array}{c}0.261 \\
(0.701)\end{array}$ & $\begin{array}{l}0.236 \\
(0.297)\end{array}$ & $\begin{array}{c}0.048 \\
(0.122)\end{array}$ \\
\hline Order 6 & $\begin{array}{c}0.034 \\
(0.103)\end{array}$ & $\begin{array}{c}0.076 \\
(0.137)\end{array}$ & $\begin{array}{c}1.067 \\
(3.073)\end{array}$ & $\begin{array}{l}-0.110 \\
(0.366)\end{array}$ & $\begin{array}{l}-0.117 \\
(0.322)\end{array}$ & $\begin{array}{c}0.602 \\
(0.591)\end{array}$ & $\begin{array}{l}-0.067 \\
(0.223)\end{array}$ & $\begin{array}{c}0.058 \\
(0.109)\end{array}$ \\
\hline Female $=1$ & $\begin{array}{c}-0.141 * * \\
(0.069)\end{array}$ & $\begin{array}{c}-0.224 * * \\
(0.087)\end{array}$ & $\begin{array}{c}-4.277 * * \\
(1.946)\end{array}$ & $\begin{array}{l}-0.011 \\
(0.286)\end{array}$ & $\begin{array}{c}0.061 \\
(0.221)\end{array}$ & $\begin{array}{l}-0.463 \\
(0.368)\end{array}$ & $\begin{array}{c}-0.358^{* *} \\
(0.152)\end{array}$ & $\begin{array}{c}0.174^{* *} \\
(0.072)\end{array}$ \\
\hline Age & $\begin{array}{l}-0.007 \\
(0.011)\end{array}$ & $\begin{array}{l}-0.011 \\
(0.014)\end{array}$ & $\begin{array}{l}-0.206 \\
(0.356)\end{array}$ & $\begin{array}{c}0.013 \\
(0.046)\end{array}$ & $\begin{array}{c}0.002 \\
(0.034)\end{array}$ & $\begin{array}{l}-0.014 \\
(0.056)\end{array}$ & $\begin{array}{l}-0.020 \\
(0.027)\end{array}$ & $\begin{array}{c}0.013 \\
(0.010)\end{array}$ \\
\hline Math related & $\begin{array}{c}0.134^{* *} \\
(0.068)\end{array}$ & $\begin{array}{c}0.104 \\
(0.087)\end{array}$ & $\begin{array}{c}3.277 \\
(2.003)\end{array}$ & $\begin{array}{c}0.873 * * * \\
(0.286)\end{array}$ & $\begin{array}{c}0.453^{* *} \\
(0.220)\end{array}$ & $\begin{array}{c}0.042 \\
(0.361)\end{array}$ & $\begin{array}{c}0.240 \\
(0.151)\end{array}$ & $\begin{array}{l}-0.093 \\
(0.067)\end{array}$ \\
\hline SES (3-4) & $\begin{array}{c}0.147^{* *} \\
(0.071)\end{array}$ & $\begin{array}{c}0.173^{* *} \\
(0.088)\end{array}$ & $\begin{array}{c}3.999 * * \\
(2.015)\end{array}$ & $\begin{array}{c}0.026 \\
(0.310)\end{array}$ & $\begin{array}{l}0.219 \\
(0.236)\end{array}$ & $\begin{array}{l}0.305 \\
(0.364)\end{array}$ & $\begin{array}{l}0.298^{*} \\
(0.156)\end{array}$ & $\begin{array}{c}-0.139 * * \\
(0.070)\end{array}$ \\
\hline SES (5-6) & $\begin{array}{c}0.571 * * * \\
(0.189)\end{array}$ & $\begin{array}{c}0.766^{* * * *} \\
(0.238)\end{array}$ & $\begin{array}{c}16.068^{* * *} \\
(4.906)\end{array}$ & $\begin{array}{c}1.718^{* * * *} \\
(0.623)\end{array}$ & $\begin{array}{c}0.426 \\
(0.627)\end{array}$ & $\begin{array}{c}2.128^{* * * *} \\
(0.807)\end{array}$ & $\begin{array}{c}0.991 * * \\
(0.486)\end{array}$ & $\begin{array}{c}-0.271^{*} \\
(0.147)\end{array}$ \\
\hline Emergency & $\begin{array}{l}-0.082 \\
(0.052)\end{array}$ & $\begin{array}{c}-0.112^{*} \\
(0.065)\end{array}$ & $\begin{array}{l}-2.331^{*} \\
(1.340)\end{array}$ & $\begin{array}{c}0.031 \\
(0.222)\end{array}$ & $\begin{array}{l}-0.050 \\
(0.156)\end{array}$ & $\begin{array}{l}-0.254 \\
(0.271)\end{array}$ & $\begin{array}{l}-0.168 \\
(0.113)\end{array}$ & $\begin{array}{c}0.029 \\
(0.049)\end{array}$ \\
\hline RET (first round) & $\begin{array}{c}0.124^{* * *} \\
(0.018)\end{array}$ & $\begin{array}{c}0.043^{* *} \\
(0.019)\end{array}$ & $\begin{array}{c}2.548 * * * \\
(0.456)\end{array}$ & & $\begin{array}{c}0.669 * * * \\
(0.061)\end{array}$ & $\begin{array}{c}0.107 \\
(0.075)\end{array}$ & $\begin{array}{l}0.061^{*} \\
(0.035)\end{array}$ & $\begin{array}{c}-0.140^{* * *} \\
(0.017)\end{array}$ \\
\hline Constant & $\begin{array}{c}-0.534^{*} \\
(0.320)\end{array}$ & $\begin{array}{c}0.035 \\
(0.403)\end{array}$ & $\begin{array}{c}37.324 * * * \\
(9.828)\end{array}$ & $\begin{array}{c}5.201 * * * \\
(1.187)\end{array}$ & $\begin{array}{c}2.120^{* *} \\
(0.998)\end{array}$ & $\begin{array}{c}13.134 * * * \\
(1.645)\end{array}$ & $\begin{array}{c}4.189 * * * \\
(0.731)\end{array}$ & $\begin{array}{l}0.592^{*} \\
(0.304)\end{array}$ \\
\hline $\begin{array}{l}\text { Number of } \\
\text { observations }\end{array}$ & 840 & 560 & 280 & 280 & 280 & 280 & 280 & 840 \\
\hline R-squared & 0.142 & 0.099 & 0.253 & 0.073 & 0.461 & 0.107 & 0.129 & 0.148 \\
\hline
\end{tabular}

Note: Same as Table S5 above but controlling for the performance in the first round of RET. 
Table S7: Regressions on Measures of Loss Aversion

\begin{tabular}{|c|c|c|c|}
\hline & Loss Averse & witch Poir & ected Lotteries \\
\hline Variables & (1) & (2) & (3) \\
\hline $\mathrm{T} 2$ & 0.044 & -0.103 & 0.038 \\
\hline & $(0.058)$ & $(0.246)$ & $(0.210)$ \\
\hline T3 & 0.006 & 0.042 & 0.017 \\
\hline & $(0.063)$ & -0.264 & $(0.235)$ \\
\hline $\mathrm{T} 4$ & -0.024 & -0.153 & 0.124 \\
\hline & $(0.063)$ & $(0.262)$ & $(0.239)$ \\
\hline Feedback & 0.033 & -0.250 & 0.227 \\
\hline & $(0.061)$ & $(0.231)$ & $(0.201)$ \\
\hline Order 2 & 0.058 & 0.037 & 0.013 \\
\hline & $(0.076)$ & $(0.315)$ & $(0.281)$ \\
\hline Order 3 & $0.125^{*}$ & -0.422 & 0.392 \\
\hline & $(0.071)$ & $(0.306)$ & $(0.269)$ \\
\hline Order 4 & 0.127 & -0.364 & 0.399 \\
\hline & $(0.085)$ & $(0.412)$ & $(0.329)$ \\
\hline Order 5 & 0.051 & -0.065 & 0.090 \\
\hline & (0.088) & $(0.387)$ & $(0.338)$ \\
\hline Order 6 & 0.026 & 0.046 & 0.008 \\
\hline & (0.083) & $(0.336)$ & $(0.299)$ \\
\hline Female $=1$ & -0.028 & 0.164 & -0.069 \\
\hline & $(0.050)$ & $(0.213)$ & $(0.179)$ \\
\hline Age & -0.002 & 0.018 & -0.015 \\
\hline & $(0.008)$ & $(0.032)$ & $(0.029)$ \\
\hline Math related & -0.042 & 0.294 & -0.245 \\
\hline & $(0.048)$ & $(0.201)$ & $(0.177)$ \\
\hline SES (3-4) & 0.034 & 0.052 & -0.044 \\
\hline & $(0.049)$ & $(0.213)$ & $(0.186)$ \\
\hline SES (5-6) & -0.044 & 0.811 & -0.469 \\
\hline & $(0.140)$ & $(0.557)$ & $(0.463)$ \\
\hline Emergency & -0.005 & 0.108 & -0.054 \\
\hline & $(0.034)$ & $(0.141)$ & $(0.117)$ \\
\hline Constant & $0.849 * * *$ & $2.322 * * *$ & $3.401 * * *$ \\
\hline & $(0.225)$ & $(0.871)$ & $(0.793)$ \\
\hline Number of observations & 241 & 241 & 280 \\
\hline R-squared & 0.038 & 0.050 & 0.038 \\
\hline
\end{tabular}

Table S7 shows the results of regressions on three measures of loss aversion. Independent variables are explained in Table S4. Column (1) shows the likelihood of being loss averse. Column (2) shows the lottery in which participants switched from accepting to rejecting lotteries (a measure of loss aversion). Column (3) shows the number of rejected lotteries. The measures of likelihood of being loss averse and the switching point require us to drop participants with multiple switching points. The number of rejected lotteries allows us to measure loss aversion while avoiding dropping multiple switchers. Robust standard Errors in parenthesis; *** $\mathrm{p}<0.01,{ }^{* *} \mathrm{p}<0.05,{ }^{*} \mathrm{p}<0.1$. 
Table S8: Regression on the Likelihood of Reporting 4 or 5 in the Cheating Game

\begin{tabular}{|c|c|}
\hline Variables & $\begin{array}{c}\text { Report_45 } \\
(1)\end{array}$ \\
\hline $\mathrm{T} 2$ & $\begin{array}{c}0.023 \\
(0.081)\end{array}$ \\
\hline T3 & $\begin{array}{l}-0.029 \\
(0.084)\end{array}$ \\
\hline $\mathrm{T} 4$ & $\begin{array}{c}0.045 \\
(0.085)\end{array}$ \\
\hline Feedback & $\begin{array}{c}0.096 \\
(0.073)\end{array}$ \\
\hline Order 2 & $\begin{array}{c}0.014 \\
(0.100)\end{array}$ \\
\hline Order 3 & $\begin{array}{l}-0.161^{*} \\
(0.097)\end{array}$ \\
\hline Order 4 & $\begin{array}{c}-0.300^{* *} \\
(0.120)\end{array}$ \\
\hline Order 5 & $\begin{array}{l}-0.141 \\
(0.116)\end{array}$ \\
\hline Order 6 & $\begin{array}{l}-0.137 \\
(0.100)\end{array}$ \\
\hline Female $=1$ & $\begin{array}{l}-0.035 \\
(0.065)\end{array}$ \\
\hline Age & $\begin{array}{l}-0.011 \\
(0.010)\end{array}$ \\
\hline Math related & $\begin{array}{c}0.098 \\
(0.061)\end{array}$ \\
\hline SES (3-4) & $\begin{array}{l}-0.121 * \\
(0.064)\end{array}$ \\
\hline SES (5-6) & $\begin{array}{l}-0.034 \\
(0.168)\end{array}$ \\
\hline Emergency & $\begin{array}{l}-0.059 \\
(0.046)\end{array}$ \\
\hline Constant & $\begin{array}{c}0.941 * * * \\
(0.268)\end{array}$ \\
\hline $\begin{array}{c}\text { Number of observations } \\
\text { R-squared }\end{array}$ & $\begin{array}{c}280 \\
0.070\end{array}$ \\
\hline
\end{tabular}

Table S8 shows the result of a regression over the likelihood of reporting numbers 4 or 5 (the highest-paying numbers). Individual controls are explained in Table S4. Robust standard Errors in parenthesis; *** $\mathrm{p}<0.01,{ }^{* *} \mathrm{p}<0.05,{ }^{*} \mathrm{p}<0.1$. 
S3.3 OLS Regressions with Robust Standard Error for Main Effects

Table S9: Regressions on Cognitive Performance (Main Effects)

\begin{tabular}{|c|c|c|c|c|c|c|c|}
\hline & \multicolumn{6}{|c|}{ Accuracy } & \multirow{2}{*}{$\begin{array}{c}\text { Response } \\
\text { Time } \\
\text { Cognitive }\end{array}$} \\
\hline & Cognitive & STM-FI & F. Component & RET & STM & FI & \\
\hline Variables & (1) & $(2)$ & (3) & (4) & $(5)$ & (6) & $(7)$ \\
\hline NIS & $\begin{array}{l}-0.015 \\
(0.068)\end{array}$ & $\begin{array}{l}-0.015 \\
(0.083)\end{array}$ & $\begin{array}{l}-0.333 \\
(2.046)\end{array}$ & $\begin{array}{l}-0.034 \\
(0.278)\end{array}$ & $\begin{array}{l}-0.171 \\
(0.347)\end{array}$ & $\begin{array}{c}0.036 \\
(0.147)\end{array}$ & $\begin{array}{c}0.087 \\
(0.069)\end{array}$ \\
\hline NWS & $\begin{array}{c}-0.174 * * * \\
(0.067)\end{array}$ & $\begin{array}{c}-0.195^{* *} \\
(0.082)\end{array}$ & $\begin{array}{c}-4.492^{* *} \\
(2.027)\end{array}$ & $\begin{array}{l}-0.307 \\
(0.275)\end{array}$ & $\begin{array}{c}-0.848^{* *} \\
(0.336)\end{array}$ & $\begin{array}{l}-0.122 \\
(0.145)\end{array}$ & $\begin{array}{c}0.153^{* *} \\
(0.068)\end{array}$ \\
\hline Feedback & $\begin{array}{c}0.179 * * \\
(0.082)\end{array}$ & $\begin{array}{c}0.280^{* * *} \\
(0.104)\end{array}$ & $\begin{array}{c}5.342^{* *} \\
(2.469)\end{array}$ & $\begin{array}{l}-0.052 \\
(0.313)\end{array}$ & $\begin{array}{l}0.816^{*} \\
(0.431)\end{array}$ & $\begin{array}{l}0.348^{*} \\
(0.181)\end{array}$ & $\begin{array}{c}-0.216^{* *} \\
(0.087)\end{array}$ \\
\hline Order 2 & $\begin{array}{c}0.115 \\
(0.110)\end{array}$ & $\begin{array}{c}0.092 \\
(0.135)\end{array}$ & $\begin{array}{c}2.666 \\
(3.162)\end{array}$ & $\begin{array}{c}0.380 \\
(0.447)\end{array}$ & $\begin{array}{c}0.560 \\
(0.593)\end{array}$ & $\begin{array}{l}-0.010 \\
(0.222)\end{array}$ & $\begin{array}{l}-0.061 \\
(0.107)\end{array}$ \\
\hline Order 3 & $\begin{array}{c}0.037 \\
(0.106)\end{array}$ & $\begin{array}{c}0.050 \\
(0.130)\end{array}$ & $\begin{array}{c}0.898 \\
(3.263)\end{array}$ & $\begin{array}{c}0.026 \\
(0.428)\end{array}$ & $\begin{array}{c}0.588 \\
(0.545)\end{array}$ & $\begin{array}{l}-0.125 \\
(0.229)\end{array}$ & $\begin{array}{l}-0.040 \\
(0.106)\end{array}$ \\
\hline Order 4 & $\begin{array}{c}-0.282 * * \\
(0.137)\end{array}$ & $\begin{array}{c}-0.348^{* *} \\
(0.169)\end{array}$ & $\begin{array}{c}-7.695^{*} \\
(3.989)\end{array}$ & $\begin{array}{l}-0.347 \\
(0.558)\end{array}$ & $\begin{array}{l}-0.984 \\
(0.716)\end{array}$ & $\begin{array}{l}-0.444 \\
(0.298)\end{array}$ & $\begin{array}{c}0.207 \\
(0.141)\end{array}$ \\
\hline Order 5 & $\begin{array}{c}0.122 \\
(0.139)\end{array}$ & $\begin{array}{c}0.161 \\
(0.168)\end{array}$ & $\begin{array}{c}3.461 \\
(4.065)\end{array}$ & $\begin{array}{c}0.101 \\
(0.560)\end{array}$ & $\begin{array}{c}0.312 \\
(0.703)\end{array}$ & $\begin{array}{c}0.267 \\
(0.299)\end{array}$ & $\begin{array}{l}-0.021 \\
(0.128)\end{array}$ \\
\hline Order 6 & $\begin{array}{c}0.023 \\
(0.108)\end{array}$ & $\begin{array}{c}0.072 \\
(0.138)\end{array}$ & $\begin{array}{c}0.836 \\
(3.306)\end{array}$ & $\begin{array}{l}-0.178 \\
(0.389)\end{array}$ & $\begin{array}{c}0.578 \\
(0.599)\end{array}$ & $\begin{array}{l}-0.066 \\
(0.228)\end{array}$ & $\begin{array}{c}0.073 \\
(0.116)\end{array}$ \\
\hline Female $=1$ & $\begin{array}{c}-0.135^{*} \\
(0.072)\end{array}$ & $\begin{array}{c}-0.223^{* *} \\
(0.087)\end{array}$ & $\begin{array}{c}-4.159 * * \\
(2.077)\end{array}$ & $\begin{array}{c}0.091 \\
(0.299)\end{array}$ & $\begin{array}{l}-0.501 \\
(0.366)\end{array}$ & $\begin{array}{c}-0.338^{* *} \\
(0.152)\end{array}$ & $\begin{array}{c}0.174^{* *} \\
(0.075)\end{array}$ \\
\hline Age & $\begin{array}{l}-0.005 \\
(0.012)\end{array}$ & $\begin{array}{l}-0.010 \\
(0.014)\end{array}$ & $\begin{array}{l}-0.160 \\
(0.388)\end{array}$ & $\begin{array}{c}0.014 \\
(0.048)\end{array}$ & $\begin{array}{l}-0.015 \\
(0.057)\end{array}$ & $\begin{array}{l}-0.018 \\
(0.027)\end{array}$ & $\begin{array}{c}0.011 \\
(0.011)\end{array}$ \\
\hline Math related & $\begin{array}{c}0.244^{* * * *} \\
(0.070)\end{array}$ & $\begin{array}{l}0.142^{*} \\
(0.085)\end{array}$ & $\begin{array}{c}5.542^{* * * *} \\
(2.130)\end{array}$ & $\begin{array}{c}1.047 * * * \\
(0.290)\end{array}$ & $\begin{array}{c}0.125 \\
(0.352)\end{array}$ & $\begin{array}{l}0.29)^{*} \\
(0.152)\end{array}$ & $\begin{array}{c}-0.216^{* * *} \\
(0.071)\end{array}$ \\
\hline SES (3-4) & $\begin{array}{c}0.151^{* *} \\
(0.075)\end{array}$ & $\begin{array}{c}0.174 * * \\
(0.089)\end{array}$ & $\begin{array}{l}4.091^{*} \\
(2.204)\end{array}$ & $\begin{array}{c}0.243 \\
(0.320)\end{array}$ & $\begin{array}{c}0.301 \\
(0.364)\end{array}$ & $\begin{array}{l}0.303^{*} \\
(0.158)\end{array}$ & $\begin{array}{c}-0.143^{*} \\
(0.074)\end{array}$ \\
\hline SES (5-6) & $\begin{array}{c}0.776 * * * \\
(0.184)\end{array}$ & $\begin{array}{c}0.837 * * * \\
(0.235)\end{array}$ & $\begin{array}{c}20.255^{* * *} \\
(4.629)\end{array}$ & $\begin{array}{l}1.526^{* *} \\
(0.693)\end{array}$ & $\begin{array}{c}2.359^{* * *} \\
(0.805)\end{array}$ & $\begin{array}{c}1.069^{* *} \\
(0.468)\end{array}$ & $\begin{array}{c}-0.511 * * * \\
(0.151)\end{array}$ \\
\hline Emergency & $\begin{array}{l}-0.070 \\
(0.055)\end{array}$ & $\begin{array}{c}-0.108^{*} \\
(0.065)\end{array}$ & $\begin{array}{l}-2.076 \\
(1.478)\end{array}$ & $\begin{array}{c}0.016 \\
(0.239)\end{array}$ & $\begin{array}{l}-0.295 \\
(0.271)\end{array}$ & $\begin{array}{l}-0.142 \\
(0.113)\end{array}$ & $\begin{array}{c}0.023 \\
(0.050)\end{array}$ \\
\hline Constant & $\begin{array}{c}0.040 \\
(0.313)\end{array}$ & $\begin{array}{c}0.237 \\
(0.384)\end{array}$ & $\begin{array}{c}48.994 * * * \\
(9.997)\end{array}$ & $\begin{array}{c}5.197 * * * \\
(1.253)\end{array}$ & $\begin{array}{c}14.087 * * * \\
(1.597)\end{array}$ & $\begin{array}{c}4.284 * * * \\
(0.682)\end{array}$ & $\begin{array}{l}-0.129 \\
(0.304)\end{array}$ \\
\hline $\begin{array}{c}\text { Number of } \\
\text { observations } \\
\text { R-squared }\end{array}$ & $\begin{array}{c}840 \\
0.069\end{array}$ & $\begin{array}{c}560 \\
0.090\end{array}$ & $\begin{array}{c}280 \\
0.154\end{array}$ & $\begin{array}{c}280 \\
0.076\end{array}$ & $\begin{array}{c}280 \\
0.096\end{array}$ & $\begin{array}{c}280 \\
0.109\end{array}$ & $\begin{array}{c}840 \\
0.056\end{array}$ \\
\hline
\end{tabular}

Table S9 reports the main effects of exposure to either NS or NWS on different measures of cognitive performance and a series of individual control variables (Variables are defined in Table S4). Estimators of standardized measures can be interpreted as percentage of standard deviations. Column (1) shows standardized accuracy grouping together the RET, STM and FI tasks into one single measure. Column (2) repeats the analysis excluding the RET. Column (3) shows accuracy results when we pool data using the first component from a Principal Component Analysis. Columns (4) to (6) show accuracy in the RET, STM and FI tasks individually. Column (7) shows the standardized response time it took participants to answer a question on average, irrespectively if the answer was correct or not. This measure groups together the RET, STM and FI tasks into one single measure. Robust standard Errors in parenthesis; ${ }^{* * *} \mathrm{p}<0.01,{ }^{* *} \mathrm{p}<0.05,{ }^{*} \mathrm{p}<0.1$. 
Table S10: Regressions on Measures of Loss Aversion (Main Effects)

\begin{tabular}{|c|c|c|c|}
\hline Variables & $\begin{array}{c}\text { Loss Averse } \\
\text { (1) }\end{array}$ & $\begin{array}{l}\text { Switch } \\
\text { Point } \\
\text { (2) }\end{array}$ & $\begin{array}{c}\text { Rejected Lotteries } \\
(3)\end{array}$ \\
\hline NIS & $\begin{array}{c}0.009 \\
(0.044)\end{array}$ & $\begin{array}{l}-0.147 \\
(0.191)\end{array}$ & $\begin{array}{c}0.070 \\
(0.167)\end{array}$ \\
\hline NWS & $\begin{array}{l}-0.030 \\
(0.044)\end{array}$ & $\begin{array}{l}-0.003 \\
(0.185)\end{array}$ & $\begin{array}{c}0.051 \\
(0.164)\end{array}$ \\
\hline Feedback & $\begin{array}{c}0.032 \\
(0.061)\end{array}$ & $\begin{array}{l}-0.251 \\
(0.230)\end{array}$ & $\begin{array}{c}0.227 \\
(0.200)\end{array}$ \\
\hline Order 2 & $\begin{array}{c}0.057 \\
(0.077)\end{array}$ & $\begin{array}{c}0.036 \\
(0.315)\end{array}$ & $\begin{array}{c}0.013 \\
(0.281)\end{array}$ \\
\hline Order 3 & $\begin{array}{l}0.123^{*} \\
(0.071)\end{array}$ & $\begin{array}{l}-0.424 \\
(0.305)\end{array}$ & $\begin{array}{c}0.393 \\
(0.269)\end{array}$ \\
\hline Order 4 & $\begin{array}{c}0.126 \\
(0.083)\end{array}$ & $\begin{array}{l}-0.366 \\
(0.412)\end{array}$ & $\begin{array}{c}0.399 \\
(0.329)\end{array}$ \\
\hline Order 5 & $\begin{array}{c}0.051 \\
(0.088)\end{array}$ & $\begin{array}{l}-0.064 \\
(0.386)\end{array}$ & $\begin{array}{c}0.091 \\
(0.337)\end{array}$ \\
\hline Order 6 & $\begin{array}{c}0.023 \\
(0.083)\end{array}$ & $\begin{array}{c}0.042 \\
(0.334)\end{array}$ & $\begin{array}{c}0.009 \\
(0.299)\end{array}$ \\
\hline Female $=1$ & $\begin{array}{l}-0.032 \\
(0.050)\end{array}$ & $\begin{array}{c}0.159 \\
(0.210)\end{array}$ & $\begin{array}{l}-0.066 \\
(0.177)\end{array}$ \\
\hline Age & $\begin{array}{l}-0.002 \\
(0.008)\end{array}$ & $\begin{array}{c}0.018 \\
(0.032)\end{array}$ & $\begin{array}{l}-0.015 \\
(0.029)\end{array}$ \\
\hline Math related & $\begin{array}{l}-0.042 \\
(0.048)\end{array}$ & $\begin{array}{c}0.293 \\
(0.201)\end{array}$ & $\begin{array}{l}-0.244 \\
(0.176)\end{array}$ \\
\hline SES (3-4) & $\begin{array}{c}0.034 \\
(0.049)\end{array}$ & $\begin{array}{c}0.052 \\
(0.213)\end{array}$ & $\begin{array}{l}-0.044 \\
(0.186)\end{array}$ \\
\hline SES (5-6) & $\begin{array}{l}-0.045 \\
(0.143)\end{array}$ & $\begin{array}{c}0.810 \\
(0.558)\end{array}$ & $\begin{array}{l}-0.473 \\
(0.459)\end{array}$ \\
\hline Emergency & $\begin{array}{l}-0.009 \\
(0.032)\end{array}$ & $\begin{array}{c}0.104 \\
(0.139)\end{array}$ & $\begin{array}{l}-0.050 \\
(0.115)\end{array}$ \\
\hline Constant & $\begin{array}{c}0.882^{* * * *} \\
(0.227)\end{array}$ & $\begin{array}{c}2.364 * * * \\
(0.851)\end{array}$ & $\begin{array}{c}3.368^{* * *} \\
(0.773)\end{array}$ \\
\hline $\begin{array}{c}\text { Number of observations } \\
\text { R-squared }\end{array}$ & $\begin{array}{c}241 \\
0.035\end{array}$ & $\begin{array}{c}241 \\
0.050\end{array}$ & $\begin{array}{c}280 \\
0.038\end{array}$ \\
\hline
\end{tabular}

Table S10 shows the main effect of NIS and NWS on three measures of loss aversion. Independent variables are explained in Table S4. Column (1) shows the likelihood of being loss averse. Column (2) shows the lottery in which participants switched from accepting to rejecting lotteries (a measure of loss aversion). Column (3) shows the number of rejected lotteries. The measures of likelihood of being loss averse and the switching point require us to drop participants with multiple switching points. The number of rejected lotteries allows us to measure loss aversion while avoiding dropping multiple switchers. Robust standard Errors in parenthesis; ${ }^{* * *} \mathrm{p}<0.01, * * \mathrm{p}<0.05, * \mathrm{p}<0.1$. 
Table S11: Regression on the Likelihood of Reporting 4 or 5 in the Cheating Game (Main Effects)

\begin{tabular}{|c|c|}
\hline Variables & $\begin{array}{c}\text { Report_45 } \\
(1)\end{array}$ \\
\hline NIS & $\begin{array}{c}0.047 \\
(0.060)\end{array}$ \\
\hline NWS & $\begin{array}{l}-0.004 \\
(0.060)\end{array}$ \\
\hline Feedback & $\begin{array}{c}0.096 \\
(0.073)\end{array}$ \\
\hline Order 2 & $\begin{array}{c}0.014 \\
(0.100)\end{array}$ \\
\hline Order 3 & $\begin{array}{l}-0.160 \\
(0.097)\end{array}$ \\
\hline Order 4 & $\begin{array}{c}-0.300^{* *} \\
(0.120)\end{array}$ \\
\hline Order 5 & $\begin{array}{l}-0.140 \\
(0.116)\end{array}$ \\
\hline Order 6 & $\begin{array}{l}-0.136 \\
(0.100)\end{array}$ \\
\hline Female $=1$ & $\begin{array}{l}-0.033 \\
(0.065)\end{array}$ \\
\hline Age & $\begin{array}{l}-0.011 \\
(0.010)\end{array}$ \\
\hline Math related & $\begin{array}{c}0.099 \\
(0.061)\end{array}$ \\
\hline SES (3-4) & $\begin{array}{l}-0.121^{*} \\
(0.064)\end{array}$ \\
\hline SES (5-6) & $\begin{array}{l}-0.037 \\
(0.169)\end{array}$ \\
\hline Emergency & $\begin{array}{l}-0.056 \\
(0.046)\end{array}$ \\
\hline Constant & $\begin{array}{c}0.916 * * * \\
(0.262)\end{array}$ \\
\hline $\begin{array}{c}\text { Number of observations } \\
\text { R-squared }\end{array}$ & $\begin{array}{c}280 \\
0.069\end{array}$ \\
\hline
\end{tabular}

Table S11 shows the main effects of NIS and NWS on the likelihood of reporting numbers 4 or 5 (the highest-paying numbers). Individual controls are explained in Table S4. Robust standard Errors in parenthesis; ${ }^{* * *} \mathrm{p}<0.01,{ }^{* *} \mathrm{p}<0.05,{ }^{*} \mathrm{p}<0.1$.

\section{S3.4 Tests for the Cheating}

To test the empirical distribution against a uniform one, which would be the result of correctly reporting in the Cheating Game, we performed two statistical tests: A simulation and a $\chi^{2}$ test.

For the simulation, we simulated a random draw of a die from a uniform distribution for 282 simulated participants. We did it 100000 times. While in the real data, 62 participants reported number 4 and 72 participants reported number 5 , that is, 134 participants in the experiment reported the highest payoff numbers, none of the 100000 simulated groups had a proportion of participants reporting these numbers greater than in the real one. The probability of seeing a simulated sample reporting 4 or 5 in larger proportion than the original data is less than 0.00001 .

For the $\chi^{2}$ test we compared observed frequencies vs. expected frequencies in the sample of 282 participants for each of the possible outcomes of rolling a fair six-sided die under the null hypothesis that the 
distributions of outcomes are the same. We reject the null hypothesis (Pearson's $\chi^{2}(5)=30.7224, p<0.001$ ). These results are reported in Table S12.

Table S12: $\chi^{2}$ test of distributions between observed and expected frequencies in the Cheating Game

\begin{tabular}{ccccc}
\hline Dice draw & Observed number & Expected Number & $\begin{array}{c}\text { Observed- } \\
\text { Expected }\end{array}$ & Pearson \\
\hline 1 & 39 & 47 & -8 & -1.167 \\
2 & 34 & 47 & -13 & -1.869 \\
3 & 47 & 47 & 0 & 0 \\
4 & 62 & 47 & 15 & 2.188 \\
5 & 72 & 47 & 25 & 3.647 \\
6 & 28 & 47 & -19 & -2.771 \\
\hline
\end{tabular}

Taken together, these results indicate that participants are indeed overreporting the numbers with the highest payoff.

Now, to see if this cheating behavior is different across experimental treatments, we conducted a $\chi^{2}$ test for independence between experimental treatments and the reported die roll. We cannot reject the null hypothesis of independence between these two variables (Pearson $\chi^{2}(15)=10.2792$, $\left.\operatorname{Pr}=0.802\right)$. Results are reported in Table S13.

Table S13: $\chi^{2}$ Test for Independence between treatments and the Reported Die Roll

\begin{tabular}{c|ccccc}
\hline $\begin{array}{c}\text { Number } \\
\text { reported }\end{array}$ & \multicolumn{5}{c}{ Treatment } \\
& 1 & 2 & 3 & 4 & Total \\
\hline 1 & 13 & 5 & 9 & 12 & 39 \\
2 & 5 & 11 & 10 & 8 & 34 \\
3 & 14 & 11 & 12 & 10 & 47 \\
4 & 17 & 16 & 14 & 15 & 62 \\
5 & 18 & 20 & 17 & 17 & 72 \\
6 & 9 & 9 & 7 & 3 & 28 \\
Total & 76 & 72 & 69 & 65 & 282 \\
\hline \multicolumn{5}{c}{ Pearson Chi2(15) $=10.2792$} & \\
\hline
\end{tabular}

Table S13 reports a $\chi^{2}$ test for independence between the reported die roll and experimental treatments in the Cheating Game. We do not have enough evidence to reject the null hypothesis of independence between these two variables. 


\section{S4 Order of Tasks}

Table S14: Order of Tasks

\begin{tabular}{ccccccc}
\hline & Order 1 & Order 2 & Order 3 & Order 4 & Order 5 & Order 6 \\
\hline & RET & RET & RET & RET & RET & RET \\
& STM & STM & FI & FI & CG & CG \\
FI & CG & STM & CG & STM & FI \\
FI & CG & FI & CG & STM & FI & STM \\
& LA & LA & LA & LA & LA & LA \\
\hline
\end{tabular}

Table S14 shows all possible ordering of tasks. To control for order effects, the order of the task was randomly chosen to be implemented by session. RET stands for Real Effort Task. STM stands for Short Term Memory Task. FI stands for Fluid Intelligence Task. CG stands for Cheating Game. LA Stands for Loss Aversion Task. RET and LA tasks were always played first and last respectively because the former was essential to introduce the experimental treatments and the last one introduced an initial endowment.

\section{S5 Power analysis and equivalence test for cheating and loss aversion}

Since we did not find effect on cheating and loss aversion, we need to make sure that lack of effect, and not power is the reason behind these results. We focus on the main effect, i.e. our $\mathrm{N}$ is equal to 210 , with a ratio between treatment and control of two-to-one. To estimate the minimum detectable effect for Loss Aversion (number of rejected lotteries), we define the significance level to be $10 \%$ as used in the Tables, the power at $80 \%$ as usual, and we used as mean of the control 3.08 and standard deviation 1.345 (these two data are taken from our sample). The estimated minimum detectable effect is 0.491 , which is equivalent to a Cohen's d of $36.5 \%$. For cheating, our outcome variable will be reporting 4 or 5 , we define the significance level to be $10 \%$ as used in the Tables, the power at $80 \%$ as usual, and we used as mean of the control .5 and standard deviation .5 (these two data are taken from our sample). The estimated minimum detectable effect is 0.183 , which is equivalent to a Cohen's $\mathrm{d}$ of $36.6 \%$. As a result, we can state that we had the power to detect a small to medium effect.

To perform equivalence test, as explained in the manuscript, we estimate the minimum size effect for which we can reject that the effect is larger. It turns out to be a standard deviation for both variables. 
Table S15: Equivalence test for loss aversion (number of rejected lotteries), $\Delta=0.5382$.

\begin{tabular}{|c|c|c|c|c|c|c|}
\hline Rejected Lotteries & $\begin{array}{l}\text { Coef. } \\
\text { (1) }\end{array}$ & $\begin{array}{l}\text { Std. Err. } \\
\text { (2) }\end{array}$ & $\begin{array}{l}\text { t1 } \\
\text { (3) }\end{array}$ & $\begin{array}{c}\mathrm{P}(\mathrm{T}>\mathrm{t} 1) \\
(4)\end{array}$ & $\begin{array}{l}\mathrm{t} 2 \\
(5) \\
\end{array}$ & $\begin{array}{c}\mathrm{P}(\mathrm{T}>\mathrm{t} 2) \\
(6)\end{array}$ \\
\hline NIS & 0.070 & 0.167 & 2.800 & 0.003 & 3.640 & 0.000 \\
\hline NWS & 0.051 & 0.164 & 2.970 & 0.002 & 3.590 & 0.000 \\
\hline Feedback & 0.227 & 0.200 & 1.560 & 0.061 & 3.820 & 0.000 \\
\hline Order 2 & 0.013 & 0.281 & 1.870 & 0.031 & 1.960 & 0.025 \\
\hline Order 3 & 0.393 & 0.269 & 0.540 & 0.295 & 3.460 & 0.000 \\
\hline Order 4 & 0.399 & 0.329 & 0.420 & 0.336 & 2.850 & 0.002 \\
\hline Order 5 & 0.091 & 0.337 & 1.330 & 0.093 & 1.870 & 0.032 \\
\hline Order 6 & 0.009 & 0.299 & 1.770 & 0.039 & 1.830 & 0.034 \\
\hline Female $=1$ & -0.066 & 0.177 & 3.420 & 0.000 & 2.680 & 0.004 \\
\hline Age & -0.015 & 0.029 & 18.930 & 0.000 & 17.930 & 0.000 \\
\hline Math Training & -0.244 & 0.176 & 4.440 & 0.000 & 1.670 & 0.048 \\
\hline SES (3-4) & -0.044 & 0.186 & 3.130 & 0.001 & 2.660 & 0.004 \\
\hline SES (5-6) & -0.473 & 0.459 & 2.200 & 0.014 & 0.140 & 0.444 \\
\hline Emergency & -0.050 & 0.115 & 5.110 & 0.000 & 4.240 & 0.000 \\
\hline Constant & 3.368 & 0.773 & -3.660 & 1.000 & 5.060 & 0.000 \\
\hline
\end{tabular}

Table S16:Equivalence test for cheating (reporting numbers 4 or 5), $\Delta=0.2002$.

\begin{tabular}{ccccccc}
\hline & Coef. & Std. Err. & $\mathrm{t} 1$ & $\mathrm{P}(\mathrm{T}>\mathrm{t} 1)$ & $\mathrm{t} 2$ & $\mathrm{P}(\mathrm{T}>\mathrm{t} 2)$ \\
Report_45 & $(1)$ & $(2)$ & $(3)$ & $(4)$ & $(5)$ & $(6)$ \\
\hline NIS & 0.047 & 0.060 & 2.550 & 0.006 & 4.110 & 0.000 \\
NWS & -0.004 & 0.060 & 3.420 & 0.000 & 3.300 & 0.001 \\
Feedback & 0.096 & 0.073 & 1.440 & 0.076 & 4.070 & 0.000 \\
Order 2 & 0.014 & 0.100 & 1.870 & 0.032 & 2.140 & 0.017 \\
Order 3 & -0.160 & 0.097 & 3.700 & 0.000 & 0.410 & 0.341 \\
Order 4 & -0.300 & 0.120 & 4.160 & 0.000 & -0.830 & 0.796 \\
Order 5 & -0.140 & 0.116 & 2.940 & 0.002 & 0.520 & 0.303 \\
Order 6 & -0.136 & 0.100 & 3.360 & 0.000 & 0.640 & 0.260 \\
Female = 1 & -0.033 & 0.065 & 3.590 & 0.000 & 2.570 & 0.005 \\
Age & -0.011 & 0.010 & 21.910 & 0.000 & 19.710 & 0.000 \\
Math Training & 0.099 & 0.061 & 1.660 & 0.049 & 4.900 & 0.000 \\
SES (3-4) & -0.121 & 0.064 & 5.030 & 0.000 & 1.240 & 0.108 \\
SES (5-6) & -0.037 & 0.169 & 1.400 & 0.081 & 0.960 & 0.169 \\
Emergency & -0.056 & 0.046 & 5.600 & 0.000 & 3.150 & 0.001 \\
Constant & 0.916 & 0.262 & -2.740 & 0.997 & 4.270 & 0.000 \\
\hline
\end{tabular}

